\title{
Inhibition of Estrogen-Related Receptor $\alpha$ Blocks Liver Steatosis and Steatohepatitis and Attenuates Triglyceride Biosynthesis
}

Chien-yu Chen, ${ }^{*}$ Yang Li, ${ }^{*}$ Ni Zeng, ${ }^{*}$ Lina He, ${ }^{*}$ Xinwen Zhang, ${ }^{*}$ Taojian Tu, ${ }^{*}$ Qi Tang, ${ }^{*}$ Mario Alba, ${ }^{*}$ Sabrina Mir, * Eileen X. Stiles, ${ }^{*}$ Handan Hong, ${ }^{*}$ Enrique Cadenas, ${ }^{* \dagger}$ Andrew A. Stolz, ${ }^{\ddagger}$ Gang Li, ${ }^{\S}$ and Bangyan L. Stiles* ${ }^{*}$

From the Pharmacology and Pharmaceutical Sciences, ${ }^{*}$ School of Pharmacy, and the Departments of Biochemistry, ${ }^{\dagger}$ Medicine, ${ }^{\ddagger}$ and Pathology, ${ }^{\boldsymbol{\top}}$ Keck School of Medicine, University of Southern California, Los Angeles, California; and the Faculty of Health Sciences, $§$ University of Macau, Macau

Accepted for publication April 12, 2021.

Address correspondence to Bangyan L. Stiles, Ph. D., Pharmacology and Pharmaceutical Sciences, University of Southern California, Los Angeles, CA 90089. E-mail: bstiles@usc.edu.

\begin{abstract}
The estrogen-related receptor (ERR) family of orphan nuclear receptors are transcriptional activators for genes involved in mitochondrial bioenergetics and metabolism. The goal of this study was to explore the role of ERR $\alpha$ in lipid metabolism and the potential effect of inhibiting ERR $\alpha$ on the development of nonalcoholic fatty liver disease (NAFLD) and nonalcoholic steatohepatitis (NASH). In the current study, three experimental mouse models: high-fat diet, high-carbohydrate diet, and a genetic model of hepatic insulin resistance where the liver hyperinsulinemia signal is mimicked via hepatic deletion of Pten (phosphatase and tensin homolog deleted on chromosome 10), the negative regulator of the insulin/ phosphatidylinositol 3-kinase signaling pathway, were used. A recently developed small-molecule inhibitor for ERR $\alpha$ was used to demonstrate that inhibiting ERR $\alpha$ blocked NAFLD development induced by either high-carbohydrate diet or high-fat diet feeding. ERR $\alpha$ inhibition also diminished lipid accumulation and attenuated NASH development in the Pten null mice. Glycerolipid synthesis was discovered as an additional mechanism for ERR $\alpha$-regulated NAFLD/NASH development and glycerophosphate acyltransferase 4 was identified as a novel transcriptional target of ERR $\alpha$. In summary, these results establish ERR $\alpha$ as a major transcriptional regulator of lipid biosynthesis in addition to its characterized primary function as a regulator for mitochondrial function. This study recognizes ERR $\alpha$ as a potential target for NAFLD/NASH treatment and elucidates novel signaling pathways regulated by ERR $\alpha$. (Am J Pathol 2021, 191: 1240-1254; https://doi.org/10.1016/j.ajpath.2021.04.007)
\end{abstract}

The prevalence of liver steatosis is about $25 \%$ of the general population and is as high as $70 \%$ in the obese population and those with type 2 diabetes. ${ }^{1,2}$ These numbers are expected to increase with the predicted increase of obesity prevalence. Although moderate steatosis is considered benign and reversible, compounding with inflammation and hepatocellular damage in nonalcoholic steatohepatitis (NASH) significantly increases the likelihood of developing fibrosis, cirrhosis, and hepatocellular carcinoma. In the absence of effective Food and Drug Administration-approved therapy, nonalcoholic fatty liver disease (NAFLD)/NASH is anticipated to become the leading cause of hepatocellular carcinoma and the primary reason for liver transplants in the next decade.
Mitochondria participate in multiple metabolic processes, and mitochondrial dysfunction has been attributed to be a major contributor for the pathogenesis of NAFLD/ NASH. $^{4}$ Mouse studies that manipulate mitochondrial proteins, such as the mitochondrial trifunctional protein and the mitochondrial, as well as the nuclear, forms of sirtuins, support a role of mitochondria in NAFLD and NASH pathogenesis. ${ }^{5,6}$ Estrogen-related receptor (ERR),

\footnotetext{
Supported by the Lee Summer research fellowship R24 AA12885 (Y.L.); NIH grant R01CA154986 (B.L.S.); University of Southern California Stevens Institute technology development grant; National Institute of Diabetes and Digestive and Kidney Diseases R01DK084241; and the University of Southern California Center for Liver Disease P30DK48522.

Disclosures: None declared.
} 
Table 1 Real-Time PCR Primers Used in Study

\begin{tabular}{|c|c|c|c|}
\hline Gene & Primer & Sequence & Amplicon size, bp \\
\hline \multirow[t]{2}{*}{$A C C$} & Forward & 5'-TCACACCTGAAGACCTTAAAGCC-3' & 152 \\
\hline & Reverse & 5'-AGCCCACACTGCTTGTACTG-3' & \\
\hline \multirow[t]{2}{*}{ AGPAT1 } & Forward & $5^{\prime}-$ AGGACGCAACGTCGAGAAC-3' & 176 \\
\hline & Reverse & 5'-GCAGTACCTCCATCATCCCAAG-3' & \\
\hline \multirow[t]{2}{*}{ AGPAT3 } & Forward & 5'-CTGCTGGTCGGCTTTGTCTT-3' & 133 \\
\hline & Reverse & $5^{\prime}-$ TCCAGAGTGAGTAGGCGAGG- $3^{\prime}$ & \\
\hline \multirow[t]{2}{*}{ CYC1 } & Forward & 5'-TCAGGCCCCTGGATACTCTT-3' & 165 \\
\hline & Reverse & 5'-GCTATTAAGTCTGCССTTTCTTCC-3' & \\
\hline \multirow[t]{2}{*}{ DGAT1 } & Forward & 5'-TATTGCGGCCAATGTCTTTGC-3' & 166 \\
\hline & Reverse & $5^{\prime}$-CACTGGAGTGATAGACTCAACCA-3' & \\
\hline \multirow[t]{2}{*}{ DGAT2 } & Forward & 5'-GAATGGGAGTGGCAATGCTAT-3' & 194 \\
\hline & Reverse & $5^{\prime}$-CCTCGAAGATCACCTGCTTGT-3' & \\
\hline \multirow[t]{2}{*}{ FASN } & Forward & $5^{\prime}-$ ACAGCGGGGAATGGGTACT-3' & 188 \\
\hline & Reverse & $5^{\prime}$-GACTGGTACAACGAGCGGAT-3' & \\
\hline \multirow[t]{2}{*}{ AGPAT1 } & Forward & 5'-TCTTTGGGTTTGCGGAATGTT-3' & 111 \\
\hline & Reverse & 5'-ATTTGGAGCTGCCTAGCCTC-3' & \\
\hline \multirow[t]{2}{*}{ GPAT4 } & Forward & $5^{\prime}$-ATTTGGAGCTGCCTAGCCTC-3' & 105 \\
\hline & Reverse & $5^{\prime}$-GACACTCTTCTCCCGAAGGC-3' & \\
\hline \multirow[t]{2}{*}{ ACADM } & Forward & $5^{\prime}$-ACAACGTGAACCAGGATTAG- $3^{\prime}$ & 83 \\
\hline & Reverse & $5^{\prime}-$ TGGCAAATTTACGAGCAGTA-3' & \\
\hline \multirow[t]{2}{*}{$A c c$} & Forward & 5'-ATGGGCGGAATGGTCTCTTTC-3' & 148 \\
\hline & Reverse & 3'-TGGGGACCTTGTCTTCATCAT-3' & \\
\hline \multirow[t]{2}{*}{ Agpat1 } & Forward & 5'-TAAGATGGCCTTCTACAACGGC-3' & 135 \\
\hline & Reverse & 5'-CCATACAGGTATTTGACGTGGAG-3' & \\
\hline \multirow[t]{2}{*}{ Agpat3 } & Forward & $5^{\prime}$-CTGCTTGCCTACCTGAAGACC-3' & 141 \\
\hline & Reverse & $5^{\prime}$-GATACGGCGGTATAGGTGCTT-3' & \\
\hline \multirow[t]{2}{*}{ Cyc1 } & Forward & $5^{\prime}$-CCAGTGCCACACCGTTGAA-3' & 136 \\
\hline & Reverse & $5^{\prime}-$ TCCCCAGATGATGCCTTTGTT-3' & \\
\hline \multirow[t]{2}{*}{ Dgat1 } & Forward & $5^{\prime}-$ TCCGTCCAGGGTGGTAGTG-3' & 199 \\
\hline & Reverse & $5^{\prime}-\mathrm{TGAACAAAGAATCTTGCAGACGA-3^{ \prime }}$ & \\
\hline \multirow[t]{2}{*}{ Dgat2 } & Forward & $5^{\prime}$-CGAGACACCATAGACTACTTGCT-3' & 126 \\
\hline & Reverse & 5'-GCGGTTCTTCAGGGTGACTG-3' & \\
\hline \multirow[t]{2}{*}{ Fasn } & Forward & $5^{\prime}$-GGAGGTGGTGATAGCCGGTAT- $3^{\prime}$ & 140 \\
\hline & Reverse & 5'-TGGGTAATCCATAGAGCCCAG-3' & \\
\hline \multirow[t]{2}{*}{ Agpat1 } & Forward & $5^{\prime}-$ ACAGTTGGCACAATAGACGTTT-3' & 139 \\
\hline & Reverse & 5'-CCTTCCATTTCAGTGTTGCAGA-3' & \\
\hline \multirow[t]{2}{*}{ Gpat4 } & Forward & $5^{\prime}-$ TCAGTTTGGTGACGCCTTCT-3' & 216 \\
\hline & Reverse & $5^{\prime}-\mathrm{TTCAATCCACCGTCCCACAG-3^{ \prime }}$ & \\
\hline \multirow[t]{2}{*}{ Acadm } & Forward & 5'-AGGGTTTAGTTTTGAGTTGACGG-3' & 110 \\
\hline & Reverse & 5'-CCCCGCTTTTGTCATATTCCG-3' & \\
\hline
\end{tabular}

alias NR3B, is an orphan nuclear receptor that plays critical roles in the transcriptional regulation of genes involved in mitochondrial bioenergetics and functions. ${ }^{7}$ ERR $\alpha$, the dominant isoform of ERR in the liver, ${ }^{8}$ binds to coactivators such as peroxisome proliferator-activated receptor $\gamma$ coactivator $1-\alpha$, to regulate the expression of genes encoding mitochondrial respiratory complexes and metabolic enzymes involved in lipid and glucose metabolisms. ${ }^{9-14}$ Among the transcriptional targets of ERR $\alpha$ are genes that make up the mitochondrial respiratory apparatus, and genes that encode enzymes for the tricarboxylic acid cycle, mitochondrial oxidative phosphorylation, and fatty acid $\beta$-oxidation. ERR $\alpha$ also regulates genes that transcribe proteins that interact with mitochondrial DNA to initiate mitochondrial gene transcription. ${ }^{8,15,16}$ Given the diverse functions of these target genes, it was hypothesized that loss of ERR $\alpha$ function would result in lower oxidative phosphorylation and suppress catabolism, leading to accumulation of lipids. Surprisingly, mice deficient for $\operatorname{ERR} \alpha\left(E_{s r r a}{ }^{-/}\right.$mice $)$ have been reported to be resistant to high-fat diet (HFD)induced obesity and NAFLD. ${ }^{17}$ In addition to promoting triglyceride breakdown during refeeding, ERR $\alpha$ also promotes triglyceride buildup during chronic conditions. ${ }^{18}$ This observation indicates that either the physiological functions of ERR $\alpha$ in metabolic regulation are more complex and depend on the metabolic state, or other unidentified target genes of $\mathrm{ERR} \alpha$ mediate its function in 
lipid metabolism. In particular, fatty acid synthase (FASn) and acetyl-CoA carboxylase (ACC), two rate-limiting lipogenic genes, were found to be potential target genes of ERR $\alpha$ transcription. ${ }^{18,19}$ In agreement with this putative function of ERR $\alpha$ in lipogenesis, ERR $\alpha$ and peroxisome proliferator-activated receptor $\gamma$ coactivator $1-\alpha$ together are shown to be required for adipogenic differentiation induced by glucocorticoid, cAMP, and insulin. ${ }^{20,21}$ Thus, ERR $\alpha$ appears to play multiple roles in the regulation of lipid metabolism, and further studies are needed to elucidate additional mechanisms that regulate ERR $\alpha$-mediated lipid buildups in NAFLD/NASH.

The current study aimed to explore the function of ERR $\alpha$ in lipid metabolism and NAFLD/NASH development. We hypothesized that inhibiting ERR $\alpha$ function will attenuate NAFLD/NASH formation and explored this hypothesis using a recently discovered small-molecule inhibitor of ERR $\alpha .22^{22}$

\section{Materials and Methods}

\section{Animals}

Three animal models were used to model NAFLD/ NASH: a high-carbohydrate diet (HCD) model where 2.5 -month-old male mice were fed a $75 \%$ by calorie carbohydrate diet (TD.99252; Envigo, Placentia, CA) for 10 days; a HFD model where 2-month-old mice were fed a $60 \%$ by calorie fat diet $(06,414$; Harlan Laboratories, Indianapolis, IN) for 2 months; and a genetic NAFLD/NASH model (Pten null) where Pten (phosphatase and tensin homolog deleted on chromosome 10), the negative regulator of phosphatidylinositol 3-kinase $(\mathrm{PI} 3 \mathrm{~K}) / \mathrm{AKT}$, is selectively deleted in the liver (PtenloxP/loxP $\left.; \mathrm{Alb}-\mathrm{Cre}^{+}\right){ }^{23,24}$ Normal chow-fed wild-type mice were used as controls. All animals were housed in a temperature-, humidity-, and light-controlled room (12hour light/dark cycle), with free access to food and water. All mice were of C57BL/6 background, and all experimental procedures were conducted according to the Institutional Animal Care and Use Committee guidelines of the University of Southern California.

The ERR $\alpha$ inhibitor, polyamide ERR-PA, and mismatched polyamide control (MM-PA) compounds, provided gratis by Dr. Peter Dervan (California Insititue of Technology, Pasadena, CA), ${ }^{22}$ were dissolved in phosphatebuffered saline containing $5 \%$ dimethyl sulfoxide in approximately $0.3 \mathrm{mg} / \mathrm{mL}$ concentration and administered via i.p. injection $(1 \mathrm{mg} / \mathrm{kg})$, as indicated. All vehicle control groups received $100 \mu \mathrm{L}$ phosphate-buffered saline supplemented with 5\% dimethyl sulfoxide.

\section{Cell Culture}

Huh7 human hepatocytes (ATCC, Manassas, VA) were cultured in Dulbecco's modified Eagle's medium
Table 2 ChIP Primers Used in Study

\begin{tabular}{lll}
\hline Gene & Primer & Sequence \\
\hline $\begin{array}{l}\text { ESRRA is the } \\
\text { official symbol } \\
\text { here. }\end{array}$ & Forward & $5^{\prime}$-GAGCGATGCATGGTCCGT-3' \\
& & \\
DGAT1 & Reverse & $5^{\prime}$-CAACTGAGCACTCGAACCGT-3' \\
& Forward & $5^{\prime}$-CCTCCGGGCCCTAGACAA-3' \\
GPAT4 & Reverse & $5^{\prime}$-CCCCGTCAGCCTCTCCA-3' \\
& Forward & $5^{\prime}$-CCCCCTAGTCCGCCAGA-3' \\
& Reverse & $5^{\prime}$-AAGCTGCGTCAGGACGTG-3' \\
\hline
\end{tabular}

ChIP, chromatin immunoprecipitation.

supplemented with $10 \%$ fetal bovine serum and $1 \%$ penicillin-streptomycin, and incubated at $37^{\circ} \mathrm{C}$ with $85 \%$ relative humidity $/ 5 \% \quad \mathrm{CO}_{2}$. For experiments using polyamides, $1 \mu \mathrm{mol} / \mathrm{L}$ of polyamides was used with dimethyl sulfoxide as a vehicle control for 24 hours.

Plasmid DNA $(4 \mu \mathrm{g})$ and siRNA (100 pmol) together with $10 \mu \mathrm{L}$ of Lipofectamine 2000 (Thermo Fisher, Waltham, MA), were added to cells growing at $70 \%$ to $90 \%$ confluence and incubated for 24 hours. siRNAs for ERR $\alpha$ and scramble control were purchased from Santa Cruz Biotechnology (Dallas, TX). siRNA for CCAAT-enhancer binding protein $\beta(\mathrm{C} / \mathrm{EBP} \beta)$ was purchased from Origene (Rockville, MD). Expression vector for $\mathrm{C} / \mathrm{EBP} \beta$ was provided by Addgene (Watertown, MA).

\section{Immunopathology}

Livers were perfused with cold phosphate-buffered saline and collected in $\mathrm{Zn}$-formalin for histology; collected in OCT compound for frozen section; and flash frozen for protein, RNA, and lipid analysis. Histologic sections were stained with hematoxylin and eosin for morphologic analysis, oil red $O$ to visualize lipid, and Sirius red to visualize liver fibrosis. Oil red $\mathrm{O}$ and Sirius red staining data were further quantified using ImageJ version 2.0 software $(\mathrm{NIH}$, Bethesda, MD; http://imagej.nih.gov/ij, last accessed February 28, 2021) with Fiji in some experiments. For each animal, 10 to 40 images were taken and scored for areas of oil red $\mathrm{O}-$ positive versus total tissue area. Immunohistochemistry was performed on liver sections with anti-pan cytokeratin antibody for visualizing cholangiocytes and anti-CD68 antibody for macrophages/monocytes.

\section{Biochemical Assays}

Total liver triglycerides (TGs) were quantified using the Folch method. The TG content was determined using a kit from Wako Chemicals (Richmond, VA) and normalized to the initial weight of the liver sample. To assess liver injury, serum alanine aminotransferase was determined using the alanine aminotransferase activity assay kit, according to manufacturer's protocol. 
RNA Isolation, qPCR, and RNA-Sequencing Analysis

Total RNA from cells and frozen liver tissues was isolated using TRIzol reagent (Invitrogen, Carlsbad, CA) following manufacturer's instruction. cDNA was produced using the Reverse Transcription System (Promega, Madison, WI). Quantitative PCR (qPCR) was performed using SYBR green qPCR mix (Thermo Fisher Scientific, Waltham, MA). Gene-specific primers used for qPCR are listed in Table 1.
RNA sequencing was performed on an Illumina (San Diego, CA) HiSeq2500 by the University of Southern California Molecular Genomics' Core. Data were processed using Partek Flow (Partek, St. Louis, MO) with $\geq 1.2$-fold change in expression and false discovery rate $<0.05$ to be considered different. The heat maps for gene expression values were analyzed using Partek Flow or Gene Set Enrichment Analysis.
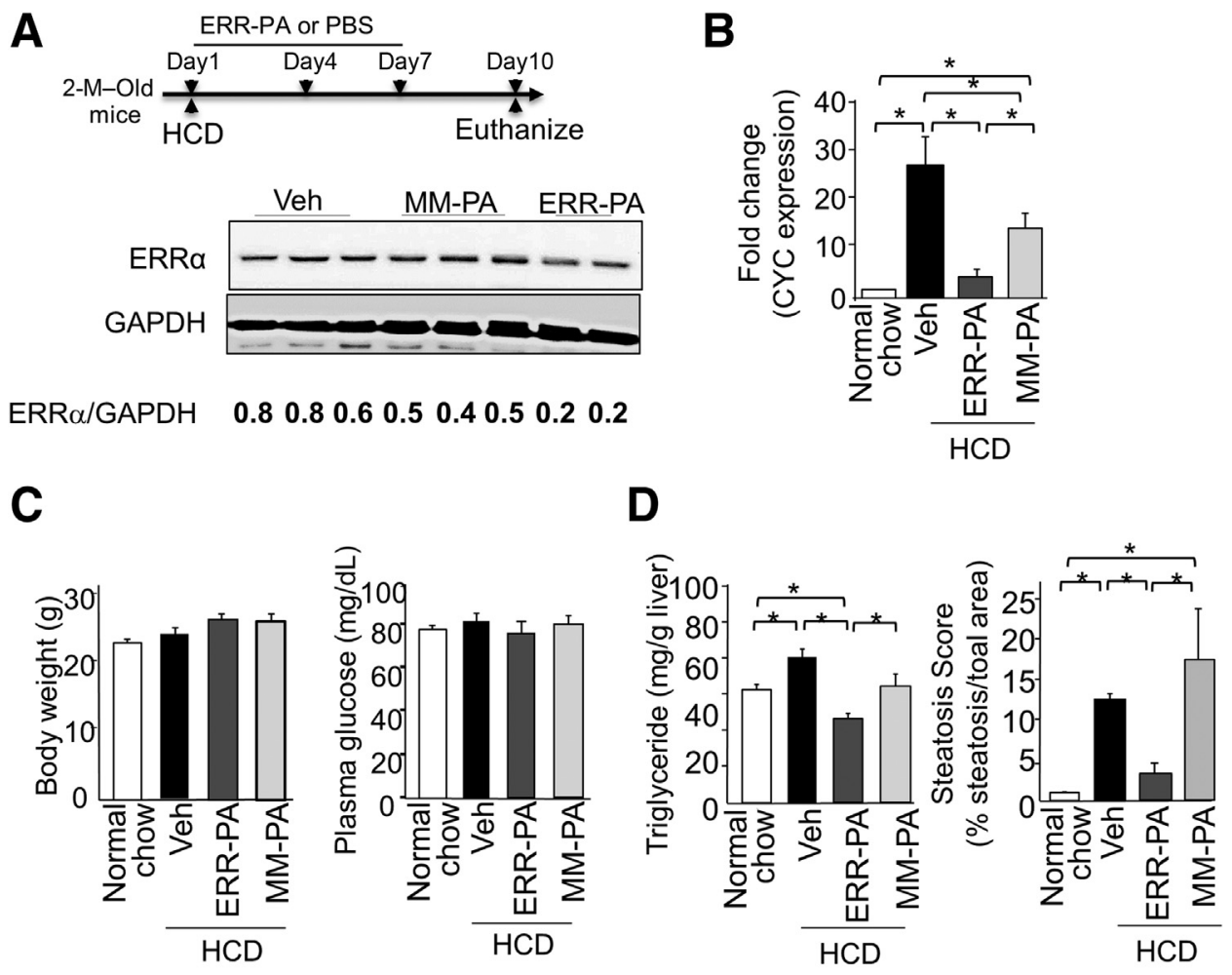

\section{$\mathbf{E}$}

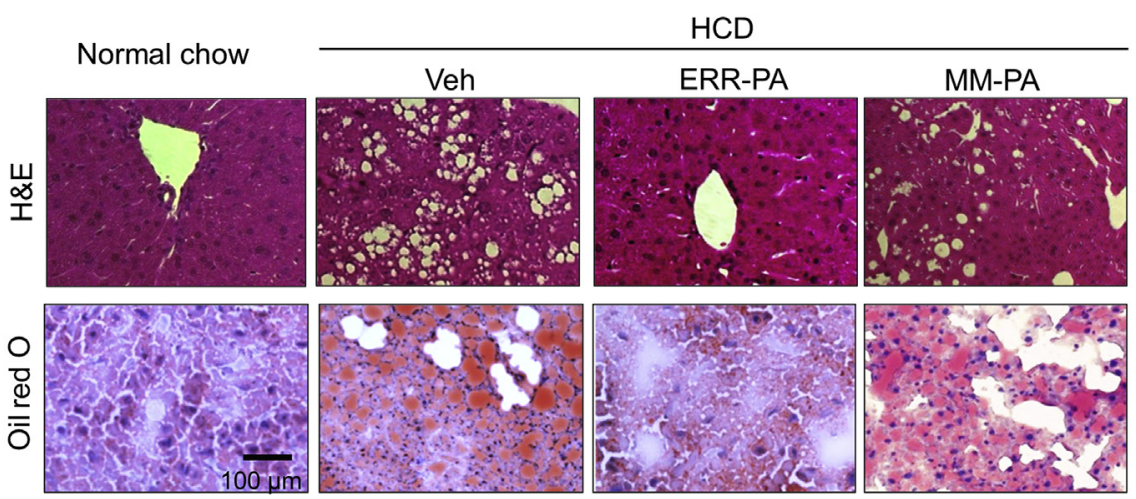

Figure 1 Treatment with the estrogen-related receptor (ERR) $\alpha$-specific inhibitor ERR-PA blocks nonalcoholic fatty liver disease (NAFLD) development in high-carbohydrate diet (HCD) fed mice. A: Top panel: Treatment protocol. Bottom panel: ERR $\alpha$ protein expression detected in HCD-NAFLD livers treated with ERR-PA (1 mg/kg), a mismatched control polyamide (MM-PA), or vehicle (Veh). Numbers below are ratio of densitometry reading of ERR $\alpha$ versus actin band. B: Quantitative PCR analysis of cytochrome $c$ (CYC) expression in livers of HCD-NAFLD mice treated with ERR-PA or vehicle control. C: Body weight and fasting plasma glucose. D: Liver triglycerides and oil red 0-positive area in different cohort of mice. E: Representative hematoxylin and eosin (H\&E; top panels) and oil red 0 staining (bottom panels) images of livers isolated from mice on normal chow or HCD treated with different compounds. $n=5$ (C); $n=5$ to 7 (D). ${ }^{*} P \leq 0.05$ between the indicated groups. Scale bar $=100 \mu \mathrm{m}(\mathrm{E})$. GAPDH, glyceraldehyde-3-phosphate dehydrogenase; PBS, phosphate-buffered saline. 


\section{Immunoblotting}

Cell and tissue lysates were prepared in protein lysis buffer supplemented with phosphatase inhibitors and protease inhibitors (Roche, Los Gatos, CA). Protein blots were probed with anti-ERR $\alpha$ (Abcam, Cambridge, UK), phosphorylated AKT (Cell Signaling Technology, Danvers, MA), PTEN (Cell Signaling Technology), and $\beta$-actin (Sigma-Aldrich, St. Louis, MO) antibodies.

\section{Chromatin Immunoprecipitation Assay}

Chromatin immunoprecipitation reaction was performed using $5 \mu \mathrm{g}$ anti-ERR $\alpha$ antibody (Abcam). Precipitated DNA samples were analyzed by quantitative PCR using SYBR green qPCR mix. The chromatin immunoprecipitationqPCR data were calculated relative to the input (ie, percentage input method). The primers used are listed in Table 2.
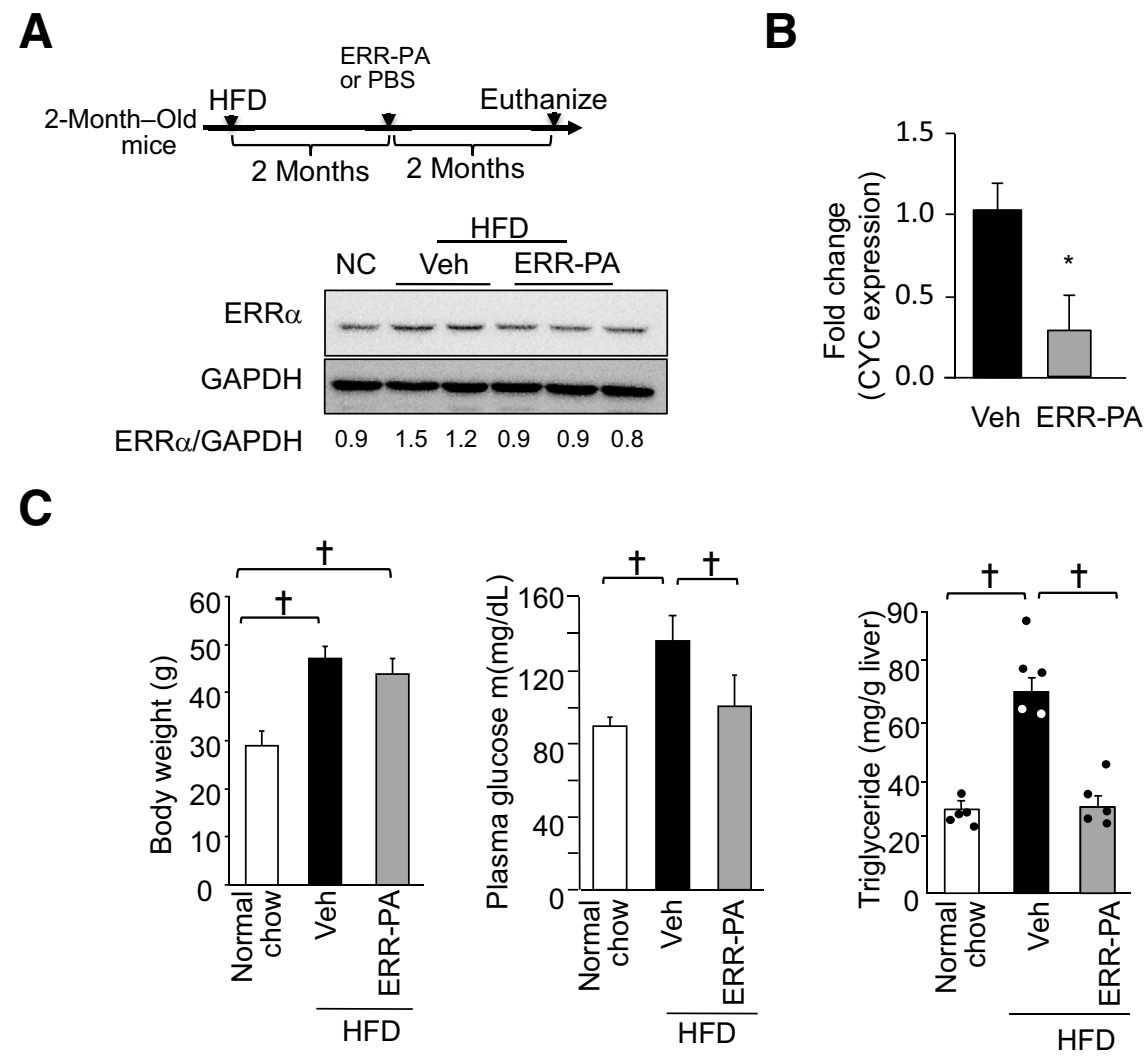

D

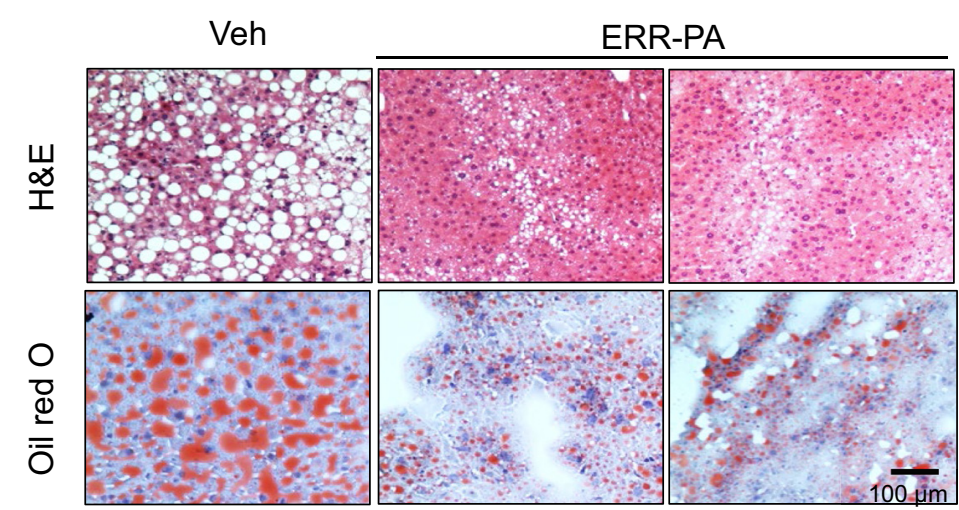

Figure 2 Inhibiting estrogen-related receptor (ERR) $\alpha$ with ERR-PA blocks the high-fat diet (HFD)-induced steatosis. A: Top panel: Treatment protocol. Bottom panel: ERR $\alpha$ protein expression detected in livers of HFD-nonalcoholic fatty liver disease (NAFLD) mice treated with ERR-PA (1 mg/kg) or vehicle (Veh). B: Quantitative PCR analysis of cytochrome $c$ (CYC) in livers of HFD-NAFLD mice treated with either ERR-PA or Veh. C: Body weight, fasting plasma glucose, and liver triglycerides in different cohort of mice. D: Representative hematoxylin and eosin (H\&E; top panels) and oil red 0 staining (bottom panels) images of livers isolated from mice on HFD treated with different compounds. $n=5$ (B and $\mathbf{C}$ ). ${ }^{\star} P \leq 0.05$ (different from the vehicle-treated group); ${ }^{\dagger} P \leq 0.05$ between the indicated groups. Scale bar $=100 \mu \mathrm{m}$ (D). GAPDH, glyceraldehyde-3-phosphate dehydrogenase; NC, normal chow; PBS, phosphate-buffered saline. 


\section{Statistical Analysis}

Data in this study were presented as means \pm SEM. For multiple-group comparison, multivariance analysis of variance was used to determine if there were intergroup differences. This was followed by the post-hoc Tukey test. For two-group comparison, data were analyzed by the two-tailed $t$-test. $P<0.05$ was considered statistically significant.

\section{Results}

\section{Inhibiting ERR $\alpha$ Attenuates NAFLD Development}

ERR $\alpha$ was up-regulated in NAFLD induced by either HCD or HFD feeding (Supplemental Figure S1). HCD or HFD fed mice were treated with ERR-PA, a recently discovered small-molecule inhibitor of ERR $\alpha .^{22}$ ERR-PA is a sequence-specific polyamide that binds to the ERR response element on the promoters of ERR target genes. It functionally inhibits oxidative phosphorylation, a primary cellular function regulated by ERR $\alpha{ }^{22}$ In Huh7 cells, RNAsequencing analysis indicates that $94.7 \%$ of differentially expressed genes altered by ERR-PA treatment are similarly altered by treatment with siRNA for ERR $\alpha$ (Supplemental Figure S2, A and B), confirming the specificity of the ERR-PA. In accordance with down-regulatiion of ERR $\alpha$ function, ERR-PA treatment robustly down-regulated mitochondrial signaling (Supplemental Figure S2C).

Lipogenesis and hepatosteatosis were induced in C56BL6 mice fed on HCD for 10 days. ${ }^{25,26}$ The HCD-fed mice were treated with ERR-PA to determine if it would inhibit the effects of HCD on hepatosteatosis (Figure 1A). As expected for the reduced ERR transcriptional activity, ERR-PA reduced the expression of cytochrome $c$ (CYC), a characterized transcriptional target for $\mathrm{ERR} \alpha$, confirming the functional inhibition of ERR $\alpha$ by treatment with ERR-PA (Figure 1B). Protein levels of ERR $\alpha$ were also reduced by ERR-PA treatment in the liver (Figure 1A). This is likely due to the function of ERR $\alpha$ as a transcriptional activator for its own transcription. ${ }^{10}$ MM-PA, a mismatch polyamide, was used as control. ${ }^{22}$ MM-PA requires $10 \times$ higher dose to disrupt the binding of ERR $\alpha$ to the estrogen related receptor response element. It also has reduced ability to inhibit expression of CYC in Huh7 cells and does not reduce luciferase activity of an estrogen related receptor response element reporter or oxygen consumption in the same cells. MM-PA treatment led to a moderate inhibition of CYC expression in the livers of HCD-fed mice. The reason for this non-specific effect of MM-PA in vivo is unclear and will need to be explored in the future. A 10-day treatment with ERR-PA or MM-PA did not cause discomfort, changes in body weight, or fasting glucose (Figure 1C). This shortterm inhibition of $E R R \alpha$ led to a $40 \%$ reduction in hepatic TG accumulation in the HCD mice (Figure 1D). Histologically, ERR-PA treatment significantly reduced the percentage of areas that stained positive for lipid with oil red $\mathrm{O}$
(Figure 1D) in the livers of the HCD mice, whereas MM-PA treatment did not. The appearance of the ERR-PA-treated livers resembled that of livers from the normal chow group (Figure 1E). These results suggest that ERR-PA treatment to inhibit $E R R \alpha$ has the potential to suppress NAFLD development.

Similar to HCD feeding, feeding HFD for 4 months increased liver TGs by more than twofold and led to a clear presence of steatosis (Figure 2). To inhibit ERR $\alpha$, HFD-fed mice were treated with ERR-PA for the last 2 months of being on the diet (Figure 2A). Similar to that in HCD mice, 2-month treatment with ERR-PA attenuated the expression of CYC (Figure 2B) and led to moderately reduced protein expression of ERR $\alpha$ (Figure 2A) in HFD mice. Treatment with ERR-PA did not reduce the body weight of the mice (Figure 2C), indicating limited overall toxicity. The weight gain, however, was reduced from $18.2 \pm 0.9$ to $14.8 \pm 1.4 \mathrm{~g}$ in the vehicle versus ERR-PA treated groups $(P=0.06)$, consistent with previous reports. ${ }^{17,18}$ Plasma glucose was also reduced in the ERR-PA treated group (Figure 2C), consistent with the role of ERR $\alpha$ in the regulation of systemic glucose metabolism. ${ }^{27} \mathrm{Next}$, the expression of phosphoenolpyruvate carboxykinase (PEPCK) and glucose-6phosphatase (G6Pase), the two key rate-limiting enzymes for gluconeogenesis reported to be transcriptional targets of $E R R \propto$, was evaluated. As expected, HFD reduced the expression of both PEPCK and G6Pase. In agreement with its glucose-lowering effect, ERR-PA reduced the expression of G6Pase in the livers of the HFD treated mice, whereas PEPCK was less responsive (Supplemental Figure S3). The expression of PEPCK and G6Pase was explored in the HCD-fed mouse livers. Consistent with an induction effect of high glucose on G6Pase, HCD induced the expression of G6Pase. Treatment of ERR-PA significantly reduced the expression of HCD-induced G6Pase, whereas PEPCK was not affected by HCD or ERR-PA treatment. The inhibition of hepatic G6Pase expression by ERR-PA in both HCD and HFD mice may have contributed to the glucose-lowering effect of ERR-PA, although a systemic effect on tissues other than the liver cannot be ruled out.

Hepatic TG accumulation was significantly reduced by more than twofold in livers of HFD mice treated with ERRPA (Figure 2C). The liver TG levels in the ERR-PA-treated mice were similar to those observed in the normal chow-fed mice. The steatosis histology was also ameliorated by ERRPA treatment, as indicated both with hematoxylin and eosin - and oil red $\mathrm{O}-$-stained tissue sections (Figure 2D).

\section{ERR $\alpha$ Inhibition Attenuates NASH Development}

A mouse model where NAFLD/NASH is induced by the loss of PTEN, a negative regulator of the insulin/PI3K/AKT signaling pathway, was used to address whether inhibiting ERR $\alpha$ could also attenuate NASH. The PI3K/AKT pathway regulates ERR $\alpha$ in hepatocytes. ${ }^{28-31}$ Deletion of Pten leads to constitutive activation of PI3K/AKT signaling 
A

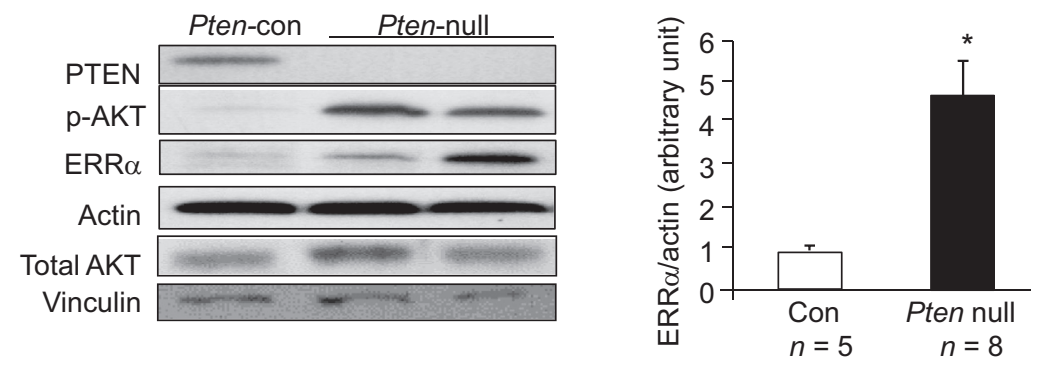

B
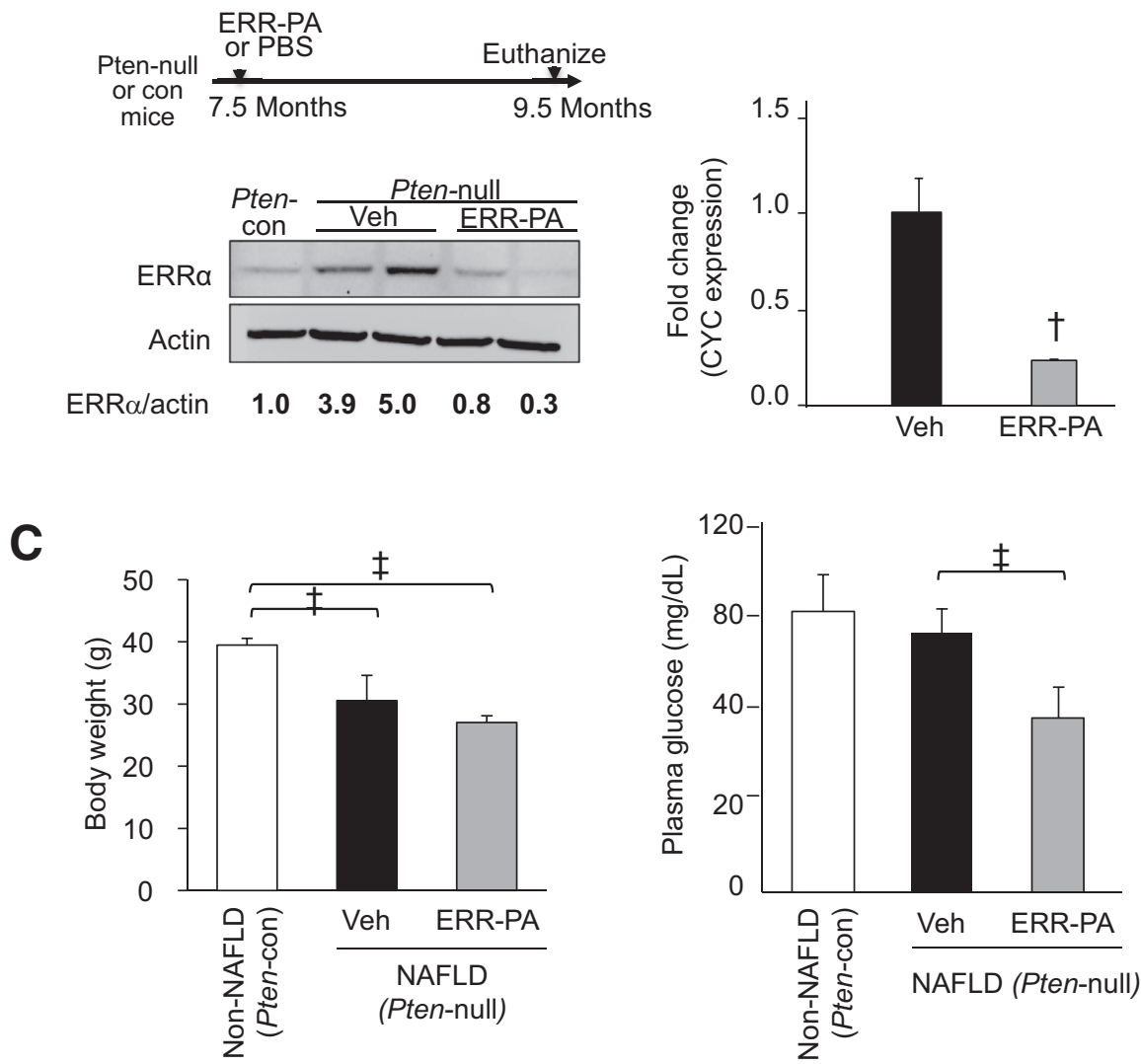

Figure 3 Estrogen-related receptor (ERR) $\alpha$ inhibition with ERR-PA in mice carrying deletion of Pten in hepatocytes. A: Left panel: ERR $\alpha$ and phosphorylated AKT ( $p-A K T)$ levels in livers of the Pten deleted (Pten-null, Pten ${ }^{\text {loxP/loxP }} ; A$ Alb-Cre ${ }^{+}$) nonalcoholic fatty liver disease (NAFLD)/nonalcoholic steatohepatitis (NASH) and control (Pten-con) non-NAFLD/NASH mice. Right panel: Densitometry quantification of ERR $\alpha$ actin ratio in all images with those in normal chow control considered to be 1. AKT and actin are detected as controls. B: Top left panel: Treatment protocol. Bottom left panel: ERR $\alpha$ protein expression detected in livers of high-fat diet-NAFLD mice treated with ERR-PA (1 mg/kg) or vehicle (Veh). Numbers below are ratio of densitometry reading of ERR $\alpha$ versus actin band. Right panel: Densitometry quantification of ERR $\alpha$ /actin ratio with those in vehicle-treated group considered to be 1 . C: Body weight and fasting plasma glucose in the different groups of mice. $n=5$ (B); $n=5$ to 7 (C). ${ }^{*} P \leq 0.05$ (different from Pten control group); ${ }^{\dagger} P \leq 0.05$ (different from the vehicle-treated group); ${ }^{\ddagger} P \leq 0.05$ between the indicated groups. PBS, phosphate-buffered saline.

downstream of insulin, mimicking the hepatic hyperinsulinemia conditions that accompany metabolic disorders, like those caused by diet feeding or obesity. ${ }^{32}$ The Pten-null NAFLD/NASH mice do not develop hyperinsulinemia outside the liver, ${ }^{24}$ allowing studying hyperinsulinemia signal-mediated steatosis in the liver without the complications of systemic metabolic changes. NAFLD develops early in the Pten deleted mice with macrovesicular lipid accumulation. ${ }^{24,32-34}$ From 7 to 9 months of age, the Ptennull mice spontaneously develop NASH-like pathologic features, including steatosis, Mallory bodies, pericellular fibrosis, and the presence of inflammatory cells. ${ }^{32,33,35,36}$ ERR $\alpha$ was elevated in the livers of the Pten-null mice, concurrent with constitutively phosphorylated AKT (Figure 3A). Treatment of 7-month-old Pten-null mice with ERR-PA for 2 months did not affect the body weight of the 
A
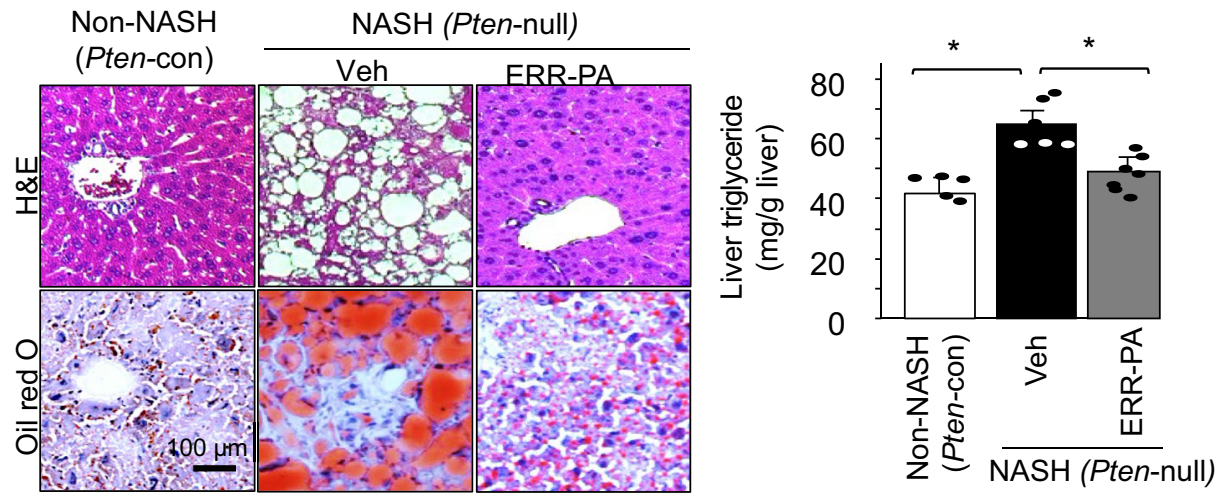

B

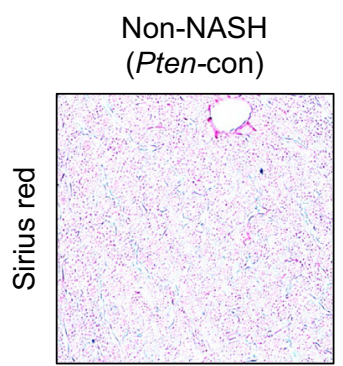

C

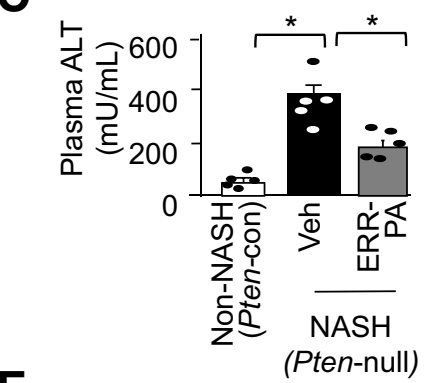

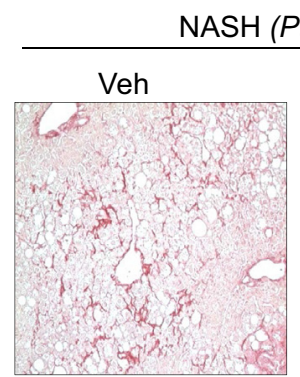

D

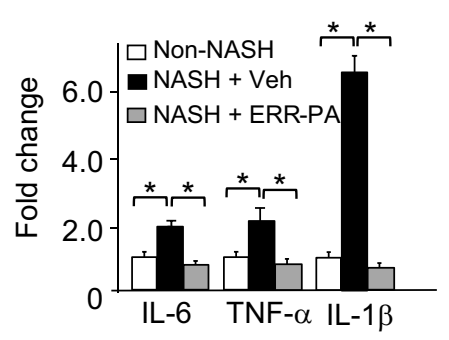

E
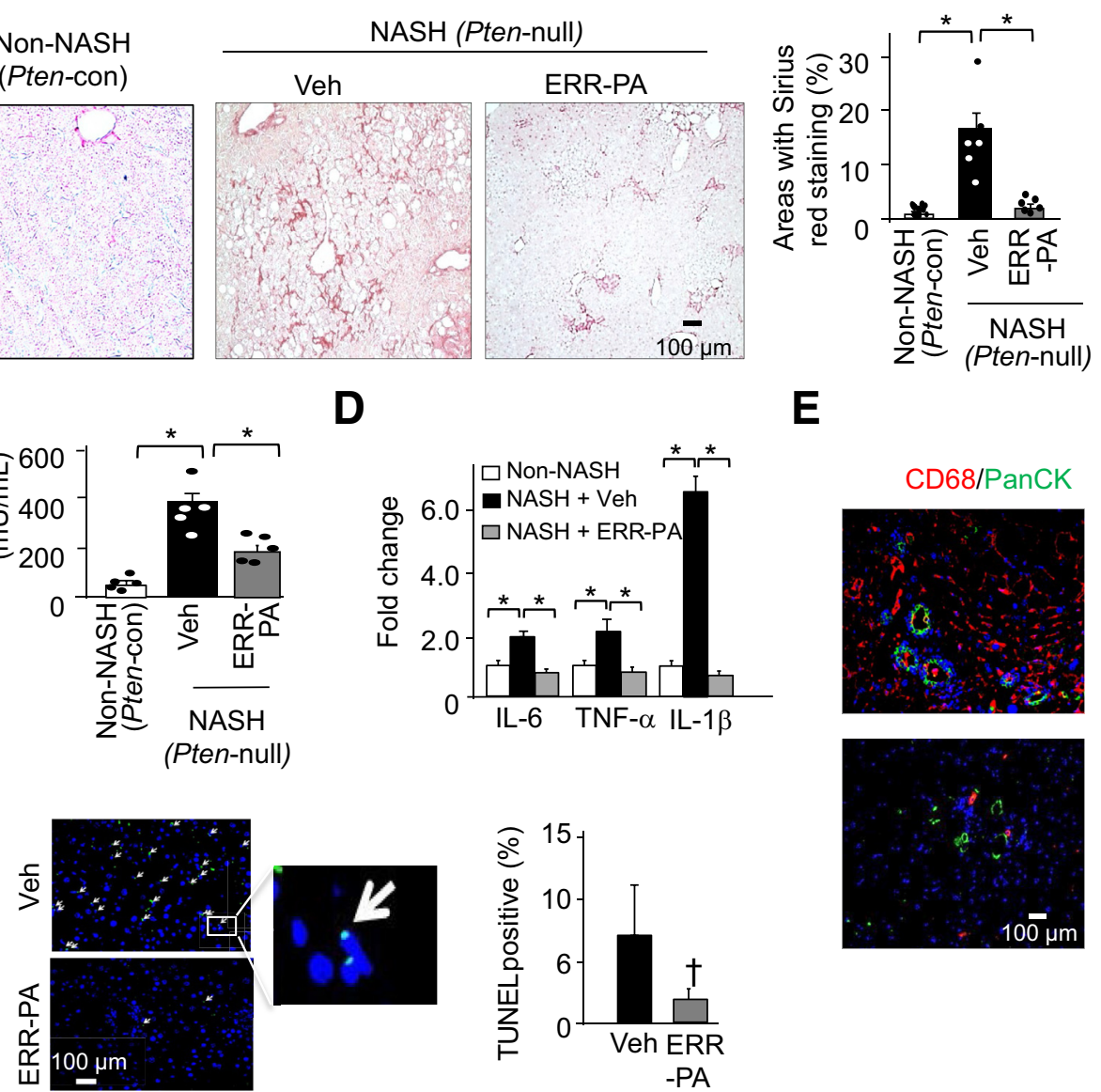

Figure 4 Estrogen-related receptor (ERR)-PA reverses nonalcoholic steatohepatitis (NASH) developed in the Pten-null mice. A: Left panel: Representative hematoxylin and eosin (H\&E) images of liver sections from 9-month-old NASH mice (Pten null) treated with ERR-PA or vehicle (Veh). Age-matched Ptencontrol (con) mice are included as non-NASH controls. Right panel: Quantification of liver triglycerides in different groups of mice. B: Left panel: Representative images of Sirius red staining in liver sections from 9-month-old NASH mice (Pten null) treated with ERR-PA or Veh. Age-matched Pten-con mice included as non-NASH controls. Right panel: Quantification of Sirius red stained liver tissue. C: Quantification of serum alanine aminotransferase (ALT). D: Quantitative PCR analysis of select inflammatory cytokines IL-6, tumor necrosis factor- $\alpha$ (TNF- $\alpha$ ), and IL-1 $\beta$. E: Immunofluorescence staining of pan cytokeratin antibody (PanCK; green)/CD68 (red) in liver sections from 9-month-old NASH mice (Pten null) treated with ERR-PA or Veh. Age-matched Pten-con mice included as non-NASH controls. Blue, DAPI. F: Left panel: Terminal deoxynucleotidyl transferase-mediated dUTP nick-end labeling (TUNEL) staining of liver tissue sections from the Pten-null NASH mice treated with or without ERR-PA. White arrows point to TUNEL-positive cells. Inset: Amplified view of the boxed area showing TUNEL (green) stained nuclei. Right panel: Quantification of the TUNEL-stained tissue sections. $n=5$ to 7 (B); $n=5$ (C, D, and F). ${ }^{*} P \leq 0.05$ between the indicated groups; ${ }^{\dagger} P \leq 0.05$ (different from the vehicle-treated group). Scale bar $=100 \mu \mathrm{m}(\mathbf{A}, \mathbf{B}, \mathbf{E}$, and $\mathbf{F})$.

mice (Figure 3, B and C), although the Pten-null mice had moderately lower body weight and blood glucose compared with the control mice, as previously reported. ${ }^{37}$ Similar to that in HFD mice, ERR-PA reduced plasma glucose in Pten- null mice (Figure 3C). Interestingly, ERR-PA treatment moderately rescued the down-regulation of G6Pase by PTEN loss, suggesting that the direct signaling regulation of ERR $\alpha$ by PTEN/AKT ${ }^{30}$ was blocked by ERR-PA 
A

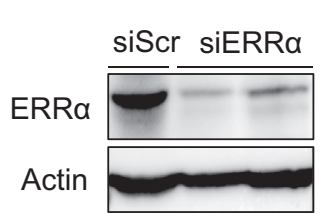

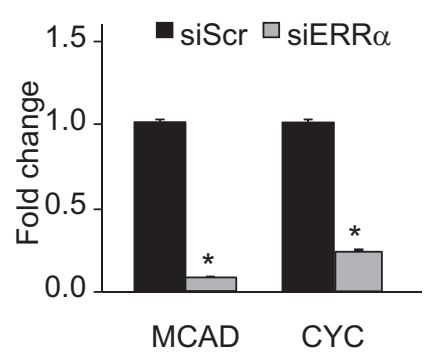

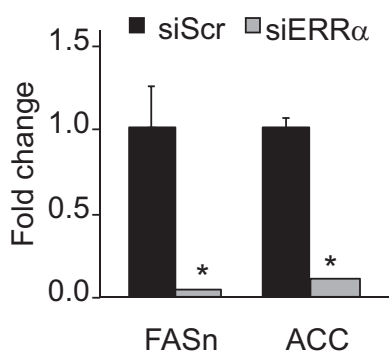

B 2.5-Month-old mice + 10days 2-Month-old mice + 2-month 7-Month Pten-null NASH

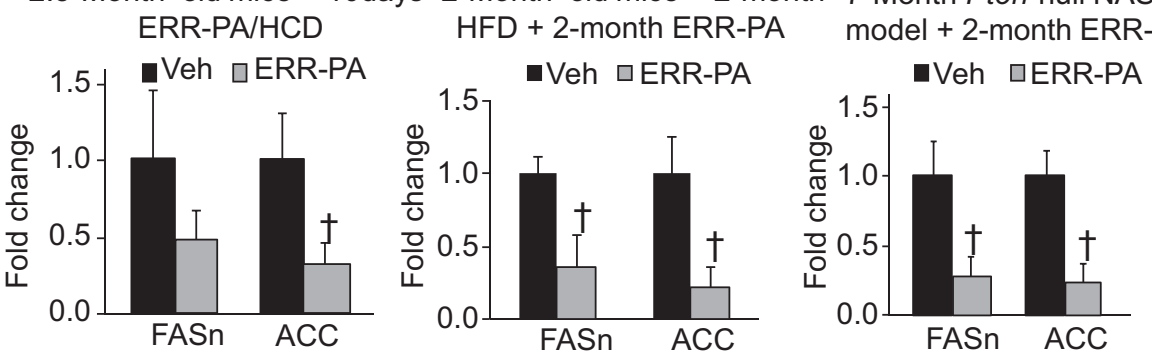

C

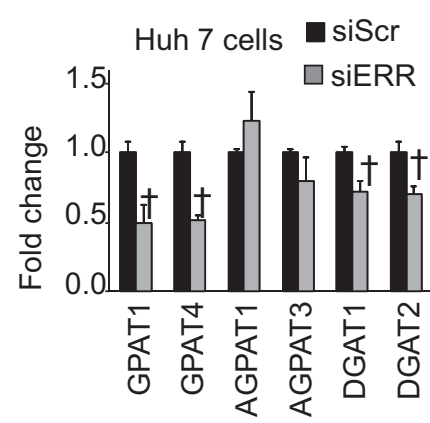

2-Month-old mice + 2-month

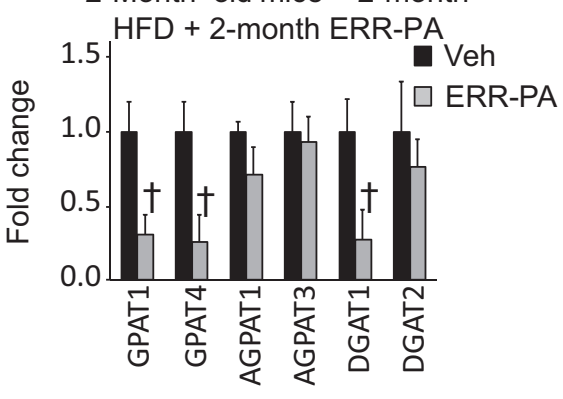

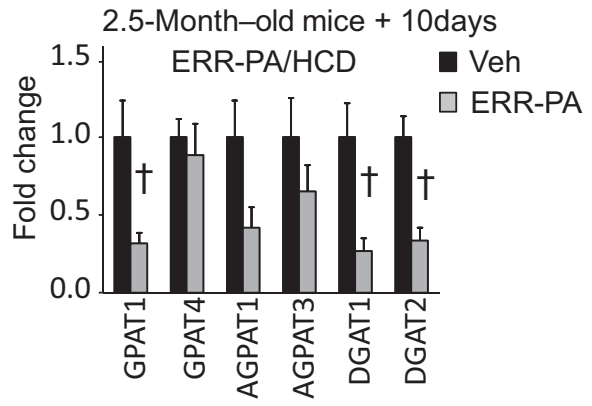

7-Month Pten-null NASH

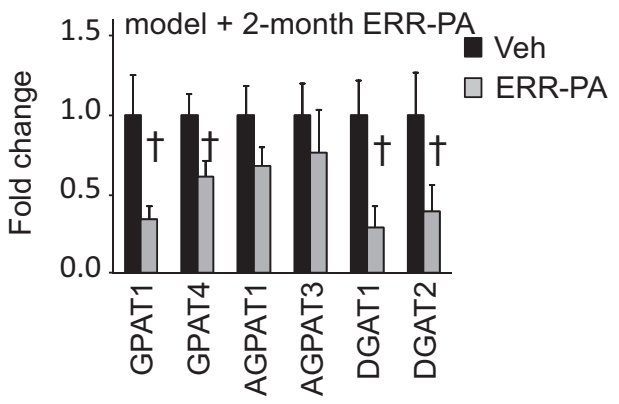

Figure 5 Regulation of de novo lipogenesis and glycerolipid biosynthesis by estrogen-related receptor (ERR) $\alpha$. A: Left panel: Protein levels of ERR $\alpha$ in Huh7 cells expressing small inhibitory ERR $\alpha$ (siERR $\alpha$ ) versus scrambled siRNA (siScr). Middle panel: Expression of ERR $\alpha$ target genes cytochrome $c$ (CYC) and medium chain acyl-CoA dehydrogenase (MCAD). Right panel: Expression of fatty acid synthase (FASn) and acetyl-CoA carboxylase (ACC), two key enzymes involved in de novo lipogenesis in siERR $\alpha$-expressing cells versus controls expressing an siScr. Experiments repeated at least three times. B: Expression of ACC and FASn in livers of high-carbohydrate diet (HCD; left panel), high-fat diet (HFD; middle panel), or Pten-null (right panel) nonalcoholic steatohepatitis (NASH) mice treated with either ERR-PA or vehicle (Veh). C: Top left panel: Quantitative PCR analysis of genes involved in glycerolipid biosynthesis in Huh7 cells expressing siERR $\alpha$ or siScr. Genes determined are: GPAT1, GPAT4, AGPAT1, AGPAT3, DGAT1, and DGAT2. Experiments repeated at least three times. Top right and bottoms panels: Expression of glycerolipid biosynthesis genes in nonalcoholic fatty liver disease/NASH models treated with ERR-PA or vehicle. Top right panel: HCD mice. Bottom left panel:, HFD mice. Bottom right panel: Pten-null NASH mice. $n=3(\mathbf{A}$ and $\mathbf{C}) ; n=5$ (B and $\mathbf{C})$. ${ }^{*} P \leq 0.05$ (different from the siScr transfected group) ${ }^{\dagger} P \leq 0.05$ (different from the vehicle-treated group).

(Supplemental Figure S3). Interestingly, PEPCK expression was not affected by ERR-PA treatment, although PTEN loss significantly down-regulated PEPCK in either vehicle or ERR-PA treated groups (Supplemental Figure S3).
Similar to that in the HCD- and HFD-treated mice, the histologic appearance of both the macrovesicular steatosis and hepatic TGs was suppressed by ERR-PA in the livers of Pten-null mice (Figure 4A). Sirius red staining for collagen 
A
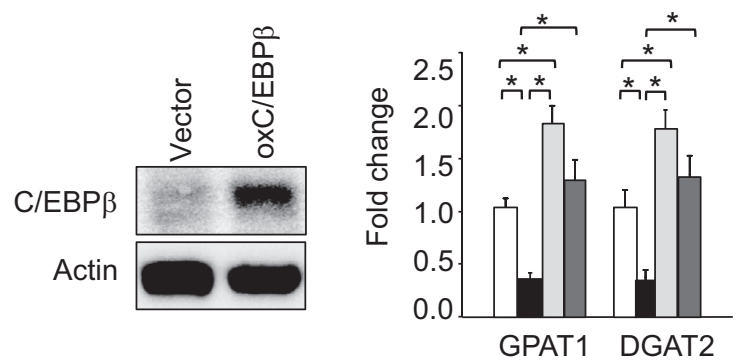

B

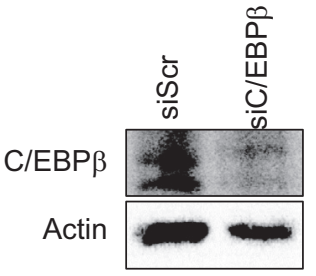

$\square$ Con $\square$ ERR-PA $\square$ oxC/EBP $\beta \quad \square$ oxC/EBP $\beta+$ ERR-PA

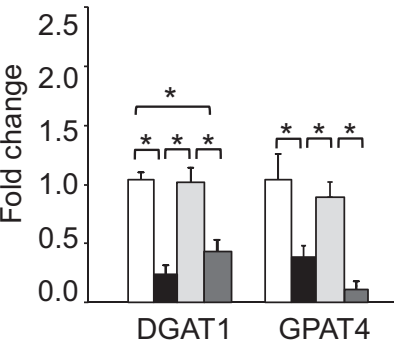

$\mathrm{siC} / \mathrm{EBP} \beta$

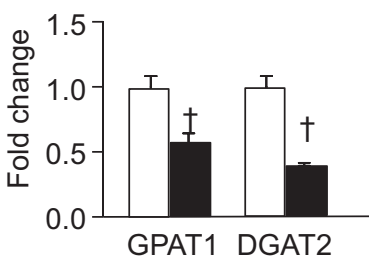

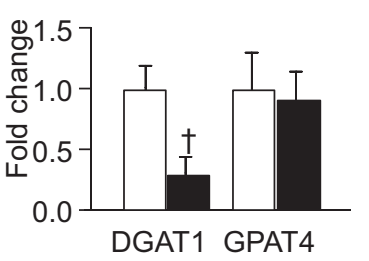

C

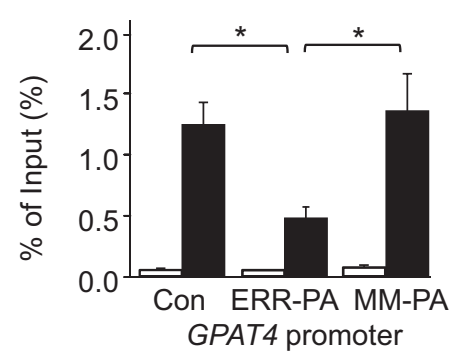

D

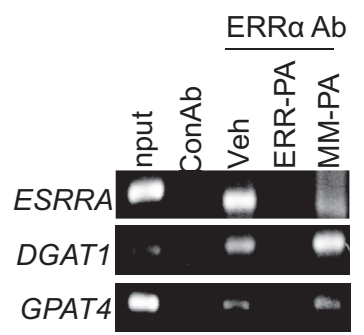

E

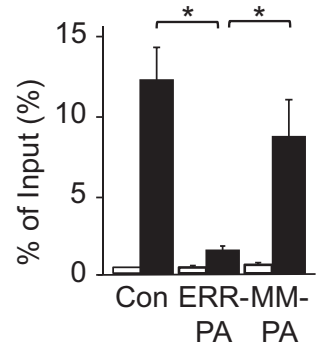

ESRRA promoter

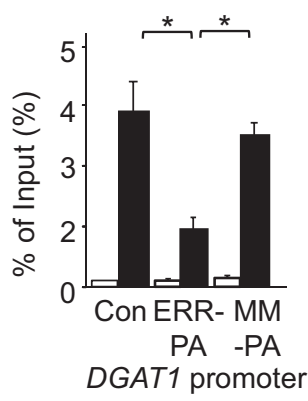

DGAT1 promoter

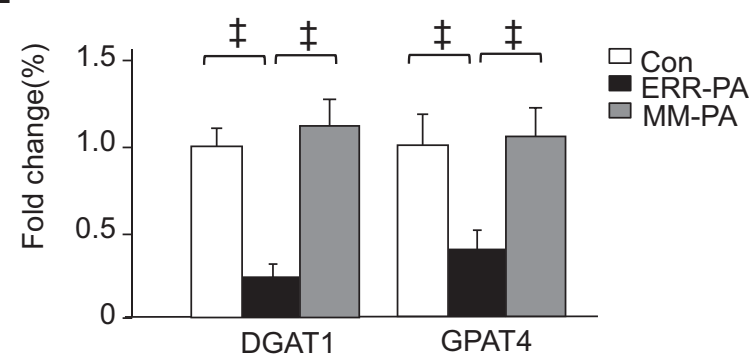

Figure 6 Regulation of GPAT4 as a novel transcriptional target of estrogen-related receptor (ERR) $\alpha$ independent of C/EBP $\beta$. A: Left panel: C/EBP $\beta$ expression in Huh7 cells with exogenous expression of C/EBP $\beta$ (oxC/EBP $\beta$ ) or vector control. Middle panel: Expression of GPAT1 and DGAT2 in vector or $C /$ EBP $\beta$ expressing Huh7 cells treated with either ERR-PA or vehicle (Veh) control. Right panel: Expression of DGAT1 and GPAT4 in vector or C/EBP $\beta$ expressing Huh7 cells treated with either ERR-PA or vehicle control. Experiments repeated at least three times. B: Left panel: C/EBP $\beta$ expression in Huh7 cells expressing $\mathrm{siC} / \mathrm{EBP} \beta$ small inhibitory C/EBP $\beta$ (siC/EBP $\beta$ ) or scrambled control (siScr). Middle panel: Expression of GPAT1 and DGAT2 in Huh7 cells expressing siC/EBP $\beta$ or siScr. Right panel: Expression of DGAT1 and GPAT4 in Huh7 cells expressing siC/EBP $\beta$ or siScr. Experiments repeated at least three times. C: Quantitative PCR analysis of GPAT4, DGAT1, and ESRRA promoters after chromatin immunoprecipitation (ChIP) with anti-ERR $\alpha$ antibody. Left panel: GPAT4 promoter. Middle and right panels: ESRRA and DGAT1 promoters used as controls. Data reported as percentage product using anti-ERR $\alpha$ or control antibody (Con-Ab) for ChIP versus total input. Input DNA (input) is PCR product amplified from samples before immunoprecipitation. Con-Ab is PCR amplification of the same fragments after ChIP with a non-specific antibody used as control. Experiments repeated twice. Treatment groups are: ERR-PA as ERR $\alpha$ inhibitor, MM-PA as compound control, and vehicle. D: Representative images of PCR products of the ESRRA, DGAT1, and GPAT4 promoters after ChIP with anti-ERR $\alpha$ antibody. E: Blockage of ERR $\alpha$ transcriptional activity by ERR-PA $(1 \mu \mathrm{mol} / \mathrm{L})$ but not MM-PA $(1 \mu \mathrm{mol} / \mathrm{L})$ led to the reduced expression of DGAT1 and GPAT4. $n=3(\mathbf{B}, \mathbf{C}$, and E). ${ }^{*} P \leq 0.05$ between the indicated groups; $\dagger P \leq 0.05$ from the siScr group; $\ddagger P \leq 0.05$. 
showed that the percentage of liver area positive for Sirius red reduced significantly from approximately $15 \%$ to $<5 \%$ (Figure 4B). Concomitantly, plasma alanine aminotransferase reduced by $50 \%$, which was indicative of less severe liver injury in the ERR-PA-treated groups (Figure 4C). The expression of IL-6, tumor necrosis factor- $\alpha$ (TNF- $\alpha$ ), and IL-1 $\beta$ was significantly reduced with ERR-PA treatment, consistent with reduced inflammation in the liver (Figure 4D). Staining with CD68 also revealed less infiltration of macrophages in the ERR-PA treated livers (Figure 4E). Deletion of Pten in the liver leads to elevated apoptosis. ${ }^{34}$ Herein, treatment with ERR-PA reduced the percentage of cells that stained positive for terminal deoxynucleotidyl transferase-mediated dUTP nick-end labeling (Figure 4F), suggesting that inhibiting ERR $\alpha$ with ERR-PA also rescued cell death. Taken together, these results suggest that ERR-PA not only blocked hepatic TG accumulation, but also substantially improved NASH pathology.

\section{Regulation of Both de Novo Lipogenesis and Glycerolipid Biosynthesis by ERR $\alpha$}

RNA sequencing in Huh7 cells expressing siRNA against ERR $\alpha$ indicated that genes encoding lipogenesis and glycerol lipid biosynthesis were regulated by ERR $\alpha$ (Supplemental Figure S4). The regulation of lipogenic genes was validated by assessing the levels of FASn and ACC, the two key regulatory enzymes in the de novo lipogenesis pathway, with down-regulated ERR $\alpha$. Introduction of ERR $\alpha$ siRNA to Huh7 cells significantly inhibited the expression of FASn and ACC in addition to the expression of the medium chain acyl-CoA dehydrogenase (MCAD) and CYC, two confirmed transcriptional targets of ERR $\alpha$ (Figure 5A). Expressions of FASn and ACC were also down-regulated in all three models where ERR-PA inhibited lipid accumulation in hepatocytes (Figure 5B). These data confirm that ERR $\alpha$-regulated de novo lipogenesis likely plays a role in the pathogenesis of NAFLD.

Free fatty acid synthesized de novo in the liver or transported from other tissues is stored into TGs via the action of enzymes that catalyze glycerolipid biosynthesis. The regulation of genes encoding these enzymes by $\operatorname{ERR} \alpha$ was verified in Huh7 cells (Figure 5C) and four of the genes were found to be significantly inhibited by the small inhibitor ERRa: glycerol-3-phophate acyltransferases [GPAT1 (alias GPAM) and GPAT4], which catalyze the conversion of glycerol-3-phosphate to lysophosphatidic acid, the first step in the glycerol lipid synthesis pathway; and diacylglycerol acyltransferases (DGAT1 and DGAT2), which catalyze the conversion of diacylglycerol to triacylglycerol, the last step of the pathway. Down-regulation of all but one of these genes by ERR $\alpha$ inhibition was also observed in the livers of all three NAFLD/NASH mouse models treated with ERR-PA (Figure 5C). The exception is GPAT4 in the HCD model, likely due to the shorter treatment duration.
Regulation of GPAT1, DGAT1, and DGAT2, but Not GPAT4, by $C / E B P \beta$

To address the mechanisms by which ERR $\alpha$ regulates the expression of these genes involved in glycerolipid synthesis, the role of C/EBP $\beta$ was explored, as GPAT1, DGAT1, and DGAT2 are transcriptional targets of C/EBP $\beta .{ }^{38,39}$ Consistent with a positive regulatory role of $\mathrm{C} / \mathrm{EBP} \beta$ on the transcription of GPAT1 and DGAT2, expression of exogenous $\mathrm{C} / \mathrm{EBP} \beta$ in Huh7 cells led to their induction compared with the untreated vector controls (Figure 6A). Although inhibiting ERR $\alpha$ with ERR-PA reduces the expression of GPAT1 and DGAT2, introduction of C/EBP $\beta$ blocks this effect. Only moderate and insignificant reduction of GPAT1 and DGAT2 is observed with the concomitant treatment of ERR-PA and expression of C/EBP $\beta$. Confirming an effect of $\mathrm{C} / \mathrm{EBP} \beta$ in the regulation of these two genes, introduction of small inhibitor $\mathrm{C} / \mathrm{EBP} \beta$ ( $\mathrm{siC} / \mathrm{EBP} \beta)$ inhibited their expression (Figure 6B). The expression of DGAT1, however, was not altered with the overexpression of C/EBP $\beta$ (Figure 6A) with or without ERR-PA treatment, suggesting that regulation of DGAT1 by ERR $\alpha$ is not dependent on C/ EBP $\beta$. Because siC/EBP $\beta$ was still capable of inhibiting its expression (Figure $6 \mathrm{~B}$ ), these data together suggest that $\mathrm{C} /$ EBP $\beta$ likely is needed to sustain DGAT1 expression but is not sufficient to induce its expression under the experimental conditions. Thus, C/EBP $\beta$ and ERR $\alpha$ may independently regulate the expression of DGAT1.

\section{Identification of GPAT4 as a Novel Transcriptional Target of ERR $\alpha$}

Although transcriptional regulation of GPAT1 has been well studied, the regulation of GPAT4 is largely unknown. ${ }^{40}$ Herein, neither siC/EBP $\beta$ nor expression of exogenous $\mathrm{C} /$ EBP $\beta$ was capable of altering the expression of GPAT4 (Figure 6, A and B). ERR-PA, however, was capable of inhibiting the expression of GPAT4 even in the presence of overexpressed C/EBP $\beta$ (Figure 6A), suggesting that the regulation of GPAT4 by ERR $\alpha$ is not mediated by C/EBP $\beta$. To explore the potential regulation of GPAT4 by ERR $\alpha$, genomic locus of GPAT4 was examined using data available from the University of California, Santa Cruz, genome browser (https://genome.ucsc.edu, last accessed May 8, 2020). A putative site for $E R R \alpha$ binding was identified in the predictive transcription initiation region, marked by $\mathrm{H} 3 \mathrm{~K} 4 \mathrm{~m} 3, \mathrm{~K} 3 \mathrm{~K} 9 \mathrm{ac}, \mathrm{K} 3 \mathrm{~K} 27 \mathrm{ac}$, and polymerase II binding (Supplemental Figure S5), similar to that in ESRRA and $D G A T 1$, two confirmed transcriptional targets of ERR $\alpha$.

To test whether ERR $\alpha$ binds to the promoter of GPAT4 to regulate its transcription, primers spanning this locus were designed to amplify the sequence after pulldown of the ERR $\alpha$-associated chromatin in Huh7 cells. Similar to DGAT1 and ESRRA used as positive controls, GPAT4 was detected in the ERR $\alpha$-associated chromatin. Furthermore, chromatin immunoprecipitation-qPCR analysis showed 
that ERR-PA significantly reduced the association of ERR $\alpha$ with this GPAT4 locus, whereas the control compound MMPA did not block the association (Figure 6, C and D). Consistently, ERR-PA treatment reduced the expression of GPAT4, but MM-PA did not (Figure 6E). Together, these data confirm that GPAT4 is a novel transcriptional target of $E R R \alpha$, and ERR-PA reduces binding of ERR $\alpha$ to the promoter of GPAT4.

\section{Discussion}

The ERR family of transcription factors are characterized for their functions in adaptive mitochondrial biogenesis in response to a variety of stimuli, including HFD, thermogenesis, and endurance exercise. ${ }^{13,27,41}$ The ERR family of nuclear receptors were discovered using the DNA-binding domain for estrogen receptor. ${ }^{42}$ This DNA binding domain shares $54 \%$ to $68 \%$ amino acid homology with other known nuclear receptors, including estrogen receptor, but has little target gene similarity. ${ }^{42,43}$ Originally defined as transcriptional factors for regulating oxidative phosphorylation through binding with cofactors, particularly peroxisome proliferator-activated receptor $\gamma$ coactivator $1,{ }^{9,14,44,45}$ ERRs also play important roles in metabolism. Although the transcriptional targets of ERRs suggest that their functions promote catabolic reactions, mice lacking ERR $\alpha$ exhibit resistance to HFD-induced obesity ${ }^{17}$ and improved sensitivity to glucose challenge, ${ }^{46}$ suggesting that the in vivo function of ERR $\alpha$ is more complicated. In this study, the function of ERR $\alpha$ in hepatic lipid homeostasis and its role in the pathogenesis of NAFLD and NASH were explored. A recently developed functional inhibitor of $\mathrm{ERR}^{22}$ was used to show that inhibiting $E R R \alpha$ transcriptional function could both block the development of NAFLD and reverse established NAFLD. In addition, ERR $\alpha$ inhibition attenuated fibrosis and inflammation that are concurrent with steatosis and NASH. $\mathrm{ERR} \alpha$ positively regulated glycerol lipid biosynthesis as well as de novo lipogenesis; and GPAT4 emerged as a novel transcriptional target of ERR $\alpha$.

Liver steatosis is often associated with impaired insulin response and system metabolic syndromes, including diabetes. In metabolic syndromes, insulin resistance occurring in muscle and adipose tissue leads to systemic hyperglycemia. The resulting hyperinsulinemia signal leads to selective hepatic insulin resistance, ${ }^{47}$ where hyperinsulinemia cannot suppress hepatic gluconeogenesis (resistance) but continues to induce lipogenesis (nonresistance), contributing to NAFLD development. Dissecting the signals downstream of AKT2 that diverge in the regulation of gluconeogenesis and lipogenesis contributed to selective insulin resistance. ${ }^{32,48,49}$ Herein, using two models (HCD and Pten null) of NAFLD where lipid accumulation results from de novo lipogenesis, ${ }^{25,50,51}$ the data established that ERR $\alpha$-mediated
FASn and ACC transcription is also important for hepatic de novo lipogenesis in vivo. ERR function has been previously reported to support adipogenesis via its binding to peroxisome proliferator-activated receptor $\gamma$ coactivator 1 to induce FASn, ACC, and sterol regulatory element binding protein, among others. ${ }^{14,20,52-54}$ Together with previous work demonstrating the regulation of ERR $\alpha$ and ERR $\gamma$ by PI3K/AKT via cAMP response element binding protein, ${ }^{30,55}$ the current data establish a signaling pathway in which hepatic hyperinsulinemia signals de novo lipogenesis via activation of AKT2. ${ }^{32,48,49}$ Activation of AKT, then, leads to induction of $E R R \alpha,{ }^{30}$ resulting in increased transcription of FASn and ACC, two rate-limiting enzymes involved in de novo lipogenesis.

In addition to de novo lipogenesis, this work also identified a novel role for ERR $\alpha$ in the storage of lipids as TGs and particularly identified GPAT4 as a novel transcriptional target of ERR $\alpha$. The storage of lipid into TG starts with esterification of long-chain fatty acids to glycerol 3phosphate, forming lysophosphatidic acid. This committed step is catalyzed by GPATs, the rate-limiting enzymes for the process. Mammals possess two mitochondrial forms of GPAT, GPAT1 (alias GPAM) and GPAT2; and two microsomal forms of GPAT (GPAT3 and GPAT4). Although GPAT2 may play other roles, all other forms of GPATs regulate glycerol lipid biosynthesis, with GPAT3 primarily functioning in white adipose tissue. ${ }^{40}$ Both GPAT1 and GPAT4 are expressed in the liver. GPAT1 and not GPAT4 is responsible for incorporating de novo synthesized fatty acids into TGs, ${ }^{56}$ whereas genetic manipulation of either leads to reduced hepatic lipid content. ${ }^{57,58}$ Although sterol regulatory element binding protein and $\mathrm{C} /$ EBP are reported to regulate the transcription of GPAT1, how GPAT2, GPAT3, and GPAT4 are regulated is largely unknown. ${ }^{38-40}$ The novel finding herein is that ERR $\alpha$ serves as the transcriptional factor for GPAT4. As a target of ERR $\alpha$, down-regulation of GPAT4 is capable of blocking the acylation of glycerol-3-phosphate at carbon 1, preventing further steps that lead to TG synthesis. This novel regulation on GPAT4 by ERR $\alpha$ may also contribute to the inhibitory effect of ERR-PA on liver steatosis in addition to its regulation of de novo lipogenesis.

Unlike NAFLD, NASH can be accompanied with inflammation and severe liver cell damage. Herein, inhibiting ERR $\alpha$ by ERR-PA not only abolished steatosis, but also attenuated the pathologic features associated with $\mathrm{NASH}$, including fibrosis. Although these observations could result from the diminished NAFLD development, a direct effect of ERR-PA on NASH cannot be ruled out. A key hypothesized pathogenesis for NAFLD/NASH-induced liver damage is reactive oxygen species. Overexpression of ERR $\alpha$ induces reactive oxygen species, whereas inhibiting ERR $\alpha$ attenuates reactive oxygen species production. ${ }^{30}$ In addition, a potential role of ERR $\alpha$ as the metabolic regulator involved in T-cell and macrophage activation has also been 
reported. ${ }^{12,59}$ How these roles of ERR $\alpha$ in inflammatory cells may affect fibrosis needs to be further investigated.

NAFLD/NASH is a complex disorder involving multiple factors. These factors ultimately lead to hepatic lipid deposition, liver injury, and inflammation, which are hallmarks of NASH. The ERRs serve as positive transcriptional regulators of genes regulating mitochondrial respiration and negative regulators for genes regulating gluconeogenesis. These characteristics have made ERRs an interesting target for the treatment of type 2 diabetes as activating ERRs has the potential to improve overall mitochondrial respiratory function and suppress hepatic glucose output. However, pharmacologic inhibition of either ERR $\alpha$ or ERR $\gamma$ (the dominant form of ERR in cardiac and skeletal muscles) has led to improved insulin response and better tolerance to dietinduced metabolic changes. ${ }^{60,61}$ This paradoxical effect of ERR inhibition on insulin sensitivity is also observed in mice lacking ERR $\alpha$ and is thought to be related to circadian rhythm regulation. ${ }^{46}$ In NAFLD induced by rapamycin treatment, lack of ERR $\alpha$ impairs fatty acid oxidation, while buildup of citrate due to downregulation of the tricarboxylic acid cycle is redirected toward lipid biosynthesis. ${ }^{19}$ Thus, the glucose-lowering effect of ERR $\alpha$ inhibition by ERR-PA may have also limited the production of citrate, playing a role in the inhibition of liver steatosis. This glucose-lowering effect of ERR inhibition may have resulted partially from the effect of ERR-PA in hepatic gluconeogenesis. Our data showed that ERR-PA treatment led to down-regulation of G6Pase in both HCD and HFD treated mouse livers, and did not alter the expression of either G6Pase or PEPCK in the Pten-deleted models. As ERRs are negative regulators of the transcription of G6Pase and PEPCK, the negative effects of ERR-PA on the expression of G6Pase suggest an off-target effect of a metabolic regulatory effect that is secondary to the primary effect of ERR-PA, likely occurring elsewhere outside the liver. To address these possibilities, a tissuespecific approach would need to be adopted to explore the function of ERR in each tissue that may contribute to glucose changes. Future work in this direction will likely improve the understanding of the biological function of ERR and its potential as a therapeutic target for metabolic diseases.

In summary, the data presented in this study demonstrated the function of ERR $\alpha$ in NAFLD/NASH development and discovered mechanisms for ERR $\alpha$-regulated lipid synthesis and storage in the liver. This study demonstrated a novel role of ERR $\alpha$ as the transcriptional factor for GPAT4 among other genes involved in glycerolipid biosynthesis, in addition to its proposed positive regulatory function in FASn and ACC. This study supports the targeting of ERR $\alpha$ as potential therapeutic intervention for NAFLD/NASH and sheds light on the paradoxical observations for the ERR $\alpha$ regulated cellular processes.

\section{Acknowledgments}

We thank the Dervan laboratory for providing the polyamide used in this study; and Dr. Bogdan Olenyuk for input into the use of the polyamide.

\section{Supplemental Data}

Supplemental material for this article can be found at http://doi.org/10.1016/j.ajpath.2021.04.007.

\section{References}

1. Fabbrini E, Sullivan S, Klein S: Obesity and nonalcoholic fatty liver disease: biochemical, metabolic, and clinical implications. Hepatology 2010, 51:679-689

2. Younossi ZM, Koenig AB, Abdelatif D, Fazel Y, Henry L, Wymer M: Global epidemiology of nonalcoholic fatty liver diseasemeta-analytic assessment of prevalence, incidence, and outcomes. Hepatology 2016, 64:73-84

3. Calzadilla Bertot L, Adams LA: The natural course of non-alcoholic fatty liver disease. Int J Mol Sci 2016, 17:774

4. Garcia-Ruiz C, Baulies A, Mari M, Garcia-Roves PM, FernandezCheca JC: Mitochondrial dysfunction in non-alcoholic fatty liver disease and insulin resistance: cause or consequence? Free Radical Res 2013, 47:854-868

5. Hirschey MD, Shimazu T, Goetzman E, Jing E, Schwer B Lombard DB, Grueter CA, Harris C, Biddinger S, Ilkayeva OR, Stevens RD, Li Y, Saha AK, Ruderman NB, Bain JR, Newgard CB, Farese RV Jr, Alt FW, Kahn CR, Verdin E: SIRT3 regulates mitochondrial fatty-acid oxidation by reversible enzyme deacetylation. Nature 2010, 464:121-125

6. Ibdah JA, Paul H, Zhao Y, Binford S, Salleng K, Cline M, Matern D Bennett MJ, Rinaldo P, Strauss AW: Lack of mitochondrial trifunctional protein in mice causes neonatal hypoglycemia and sudden death. J Clin Invest 2001, 107:1403-1409

7. Hummasti S, Tontonoz P: Adopting new orphans into the family of metabolic regulators. Mol Endocrinol 2008, 22:1743-1753

8. Bookout AL, Jeong Y, Downes M, Yu RT, Evans RM, Mangelsdorf DJ: Anatomical profiling of nuclear receptor expression reveals a hierarchical transcriptional network. Cell 2006, 126: 789-799

9. Schreiber SN, Emter R, Hock MB, Knutti D, Cardenas J, Podvinec M, Oakeley EJ, Kralli A: The estrogen-related receptor alpha (ERRalpha) functions in PPARgamma coactivator 1alpha (PGC-1alpha)-induced mitochondrial biogenesis. Proc Natl Acad Sci U S A 2004, 101:6472-6477

10. Schreiber SN, Knutti D, Brogli K, Uhlmann T, Kralli A: The transcriptional coactivator PGC-1 regulates the expression and activity of the orphan nuclear receptor estrogen-related receptor alpha (ERRalpha). J Biol Chem 2003, 278:9013-9018

11. Shao D, Liu Y, Liu X, Zhu L, Cui Y, Cui A, Qiao A, Kong X, Liu Y, Chen Q, Gupta N, Fang F, Chang Y: PGC-1 beta-regulated mitochondrial biogenesis and function in myotubes is mediated by NRF-1 and ERR alpha. Mitochondrion 2010, 10:516-527

12. Sonoda J, Laganiere J, Mehl IR, Barish GD, Chong LW, Li X, Scheffler IE, Mock DC, Bataille AR, Robert F, Lee CH, Giguere V, Evans RM: Nuclear receptor ERR alpha and coactivator PGC-1 beta are effectors of IFN-gamma-induced host defense. Genes Dev 2007, 21:1909-1920

13. Vercauteren K, Gleyzer N, Scarpulla RC: Short hairpin RNAmediated silencing of PRC (PGC-1-related coactivator) results in a 
severe respiratory chain deficiency associated with the proliferation of aberrant mitochondria. J Biol Chem 2009, 284:2307-2319

14. Kamei Y, Ohizumi H, Fujitani Y, Nemoto T, Tanaka T, Takahashi N, Kawada T, Miyoshi M, Ezaki O, Kakizuka A: PPARgamma coactivator 1 beta/ERR ligand 1 is an ERR protein ligand, whose expression induces a high-energy expenditure and antagonizes obesity. Proc Natl Acad Sci U S A 2003, 100:12378-12383

15. Dufour CR, Wilson BJ, Huss JM, Kelly DP, Alaynick WA, Downes M, Evans RM, Blanchette M, Giguere V: Genome-wide orchestration of cardiac functions by the orphan nuclear receptors ERRalpha and gamma. Cell Metab 2007, 5:345-356

16. Charest-Marcotte A, Dufour CR, Wilson BJ, Tremblay AM, Eichner LJ, Arlow DH, Mootha VK, Giguere V: The homeobox protein Prox 1 is a negative modulator of ERR $\{$ alpha\}/PGC-1 1 alpha $\}$ bioenergetic functions. Genes Dev 2010, 24:537-542

17. Sladek JR, Carrier J, Bader JA, Richard D, Giguere V: Reduced fat mass in mice lacking orphan nuclear receptor estrogen-related receptor alpha. Mol Cell Biol 2003, 23:7947-7956

18. B'Chir W, Dufour CR, Ouellet C, Yan M, Tam IS, Andrzejewski S, Xia H, Nabata K, St-Pierre J, Giguere V: Divergent role of estrogenrelated receptor alpha in lipid- and fasting-induced hepatic steatosis in mice. Endocrinology 2018, 159:2153-2164

19. Chaveroux C, Eichner LJ, Dufour CR, Shatnawi A, Khoutorsky A, Bourque G, Sonenberg N, Giguere V: Molecular and genetic crosstalks between mTOR and ERRalpha are key determinants of rapamycin-induced nonalcoholic fatty liver. Cell Metab 2013, 17: $586-598$

20. Ijichi N, Ikeda K, Horie-Inoue K, Yagi K, Okazaki Y, Inoue S: Estrogen-related receptor alpha modulates the expression of adipogenesis-related genes during adipocyte differentiation. Biochem Biophys Res Commun 2007, 358:813-818

21. Ju D, He J, Zhao L, Zheng X, Yang G: Estrogen related receptor alpha-induced adipogenesis is PGC-1beta-dependent. Mol Biol Rep 2012, 39:3343-3354

22. Chen C-Y, Li Y, Jia T, He L, Hare AA, Silberstain A, Gallagher J, Martinez TF, Stiles JW, Olenyuk B, Dervan PB, Stiles BL: Repression of the transcriptional activity of ERR $\alpha$ with sequence-specific DNA-binding polyamides. Med Chem Res 2020, 27:607-616

23. Horie Y, Suzuki A, Kataoka E, Sasaki T, Hamada K, Sasaki J, Mizuno K, Hasegawa G, Kishimoto H, lizuka M, Naito M, Enomoto K, Watanabe S, Mak TW, Nakano T: Hepatocyte-specific Pten deficiency results in steatohepatitis and hepatocellular carcinomas. J Clin Invest 2004, 113:1774-1783

24. Stiles B, Wang Y, Stahl A, Bassilian S, Lee WP, Kim YJ, Sherwin R, Devaskar S, Lesche R, Magnuson MA, Wu H: Liver-specific deletion of negative regulator Pten results in fatty liver and insulin hypersensitivity [corrected]. Proc Natl Acad Sci U S A 2004, 101: 2082-2087

25. Ferramosca A, Conte A, Damiano F, Siculella L, Zara V: Differential effects of high-carbohydrate and high-fat diets on hepatic lipogenesis in rats. Eur J Nutr 2014, 53:1103-1114

26. Palian BM, Rohira AD, Johnson SA, He L, Zheng N, Dubeau L, Stiles BL, Johnson DL: Maf1 is a novel target of PTEN and PI3K signaling that negatively regulates oncogenesis and lipid metabolism. PLoS Genet 2014, 10:e1004789

27. Villena JA, Kralli A: ERRalpha: a metabolic function for the oldest orphan. Trends Endocrinol Metab 2008, 19:269-276

28. Ariazi EA, Kraus RJ, Farrell ML, Jordan VC, Mertz JE: Estrogenrelated receptor alphal transcriptional activities are regulated in part via the ErbB2/HER2 signaling pathway. Mol Cancer Res 2007, 5: $71-85$

29. Bonnelye E, Reboul P, Duval N, Cardelli M, Aubin JE: Estrogen receptor-related receptor alpha regulation by interleukin-1beta in prostaglandin E(2)- and cAMP-dependent pathways in osteoarthritic chondrocytes. Arthritis Rheum 2011, 63:2374-2384

30. Li Y, He L, Zeng N, Sahu D, Cadenas E, Shearn C, Li W, Stiles BL: Phosphatase and tensin homolog deleted on chromosome 10 (PTEN) signaling regulates mitochondrial biogenesis and respiration via estrogen-related receptor alpha (ERRalpha). J Biol Chem 2013, 288: 25007-25024

31. Liu D, Benlhabib H, Mendelson CR: cAMP enhances estrogenrelated receptor alpha (ERRalpha) transcriptional activity at the SPA promoter by increasing its interaction with protein kinase A and steroid receptor coactivator 2 (SRC-2). Mol Endocrinol 2009, 23: $772-783$

32. He L, Hou X, Kanel G, Zeng N, Galicia V, Wang Y, Yang J, Wu H, Birnbaum MJ, Stiles BL: The critical role of AKT2 in hepatic steatosis induced by PTEN loss. Am J Pathol 2010, 176:2302-2308

33. Debebe A, Medina V, Chen CY, Mahajan IM, Jia C, Fu D, He L, Zeng N, Stiles BW, Chen CL, Wang M, Aggarwal KR, Peng Z, Huang J, Chen J, Li M, Dong T, Atkins S, Borok Z, Yuan W, Machida K, Ju C, Kahn M, Johnson D, Stiles BL: Wnt/beta-catenin activation and macrophage induction during liver cancer development following steatosis. Oncogene 2017, 36:6020-6029

34. Galicia VA, He L, Dang H, Kanel G, Vendryes C, French BA, Zeng N, Bayan JA, Ding W, Wang KS, French S, Birnbaum MJ, Rountree CB, Stiles BL: Expansion of hepatic tumor progenitor cells in Pten-null mice requires liver injury and is reversed by loss of AKT2. Gastroenterology 2010, 139:2170-2182

35. He L, Gubbins J, Peng Z, Medina V, Fei F, Asahina K, Wang J, Kahn M, Rountree CB, Stiles BL: Activation of hepatic stellate cell in Pten null liver injury model. Fibrogenesis Tissue Repair 2016, 9:8

36. Zeng N, Li Y, He L, Xu X, Galicia V, Deng CX, Stiles BL: Adaptive basal phosphorylation of eIF2\{alpha\} is responsible for resistance to cellular stress induced cell death in Pten null hepatocytes. Mol Cancer Res 2011, 9:1708-1717

37. Jia C, Medina V, Liu C, He L, Qian D, Taojian T, Okamoto CT, Stiles BL: Crosstalk of LKB1- and PTEN-regulated signals in liver morphogenesis and tumor development. Hepatol Commun 2017, 1: 153-167

38. Payne VA, Au WS, Gray SL, Nora ED, Rahman SM, Sanders R, Hadaschik D, Friedman JE, O'Rahilly S, Rochford JJ: Sequential regulation of diacylglycerol acyltransferase 2 expression by CAAT/enhancer-binding protein beta (C/EBPbeta) and C/EBPalpha during adipogenesis. J Biol Chem 2007, 282:21005-21014

39. Satoh S, Onomura D, Ueda Y, Dansako H, Honda M, Kaneko S, Kato N: Ribavirin-induced down-regulation of CCAAT/enhancerbinding protein alpha leads to suppression of lipogenesis. Biochem J 2019, 476:137-149

40. Karasawa K, Tanigawa K, Harada A, Yamashita A: Transcriptional regulation of acyl-coA:glycerol-sn-3-phosphate acyltransferases. Int J Mol Sci 2019, 20:964

41. Scarpulla RC: Nuclear control of respiratory gene expression in mammalian cells. J Cell Biochem 2006, 97:673-683

42. Giguere V, Yang N, Segui P, Evans RM: Identification of a new class of steroid hormone receptors. Nature 1988, 331:91-94

43. Deblois G, Hall JA, Perry MC, Laganiere J, Ghahremani M, Park M, Hallett M, Giguere V: Genome-wide identification of direct target genes implicates estrogen-related receptor alpha as a determinant of breast cancer heterogeneity. Cancer Res 2009, 69:6149-6157

44. Hong H, Yang L, Stallcup MR: Hormone-independent transcriptional activation and coactivator binding by novel orphan nuclear receptor ERR3. J Biol Chem 1999, 274:22618-22626

45. Huss JM, Torra IP, Staels B, Giguere V, Kelly DP: Estrogen-related receptor alpha directs peroxisome proliferator-activated receptor alpha signaling in the transcriptional control of energy metabolism in cardiac and skeletal muscle. Mol Cell Biol 2004, 24:9079-9091

46. Dufour CR, Levasseur MP, Pham NH, Eichner LJ, Wilson BJ, Charest-Marcotte A, Duguay D, Poirier-Heon JF, Cermakian N, Giguere V: Genomic convergence among ERRalpha, PROX1, and BMAL1 in the control of metabolic clock outputs. PLoS Genet 2011, 7:e1002143

47. Brown MS, Goldstein JL: Selective versus total insulin resistance: a pathogenic paradox. Cell Metab 2008, 7:95-96 
48. Leavens KF, Easton RM, Shulman GI, Previs SF, Birnbaum MJ Akt2 is required for hepatic lipid accumulation in models of insulin resistance. Cell Metab 2009, 10:405-418

49. He L, Li Y, Zeng N, Stiles BL: Regulation of basal expression of hepatic PEPCK and G6Pase by AKT2. Biochem J 2020, 477:1021-1031

50. Moon BC, Hernandez-Ono A, Stiles B, Wu H, Ginsberg HN: Apolipoprotein B secretion is regulated by hepatic triglyceride, and not insulin, in a model of increased hepatic insulin signaling. Arterioscler Thromb Vasc Biol 2012, 32:236-246

51. Stiles BL, Kuralwalla-Martinez C, Guo W, Gregorian C, Wang Y, Tian J, Magnuson MA, Wu H: Selective deletion of Pten in pancreatic beta cells leads to increased islet mass and resistance to STZ-induced diabetes. Mol Cell Biol 2006, 26:2772-2781

52. Delhon I, Gutzwiller S, Morvan F, Rangwala S, Wyder L, Evans G, Studer A, Kneissel M, Fournier B: Absence of estrogen receptorrelated-alpha increases osteoblastic differentiation and cancellous bone mineral density. Endocrinology 2009, 150:4463-4472

53. Kim DK, Kim YH, Lee JH, Jung YS, Kim J, Feng R, Jeon TI, Lee IK, Cho SJ, Im SS, Dooley S, Osborne TF, Lee CH, Choi HS: Estrogenrelated receptor gamma controls sterol regulatory element-binding protein-1c expression and alcoholic fatty liver. Biochim Biophys Acta Mol Cell Biol Lipids 2019, 1864:158521

54. Nickols NG, Szablowski JO, Hargrove AE, Li BC, Raskatov JA, Dervan PB: Activity of a Py-Im polyamide targeted to the estrogen response element. Mol Cancer Ther 2013, 12:675-684

55. Kim DK, Kim YH, Hynx D, Wang Y, Yang KJ, Ryu D, Kim KS, Yoo EK, Kim JS, Koo SH, Lee IK, Chae HZ, Park J, Lee CH, Biddinger SB, Hemmings BA, Choi HS: PKB/Akt phosphorylation of ERRgamma contributes to insulin-mediated inhibition of hepatic gluconeogenesis. Diabetologia 2014, 57:2576-2585
56. Wendel AA, Cooper DE, Ilkayeva OR, Muoio DM, Coleman RA: Glycerol-3-phosphate acyltransferase (GPAT)-1, but not GPAT4, incorporates newly synthesized fatty acids into triacylglycerol and diminishes fatty acid oxidation. J Biol Chem 2013, 288: 27299-27306

57. Neschen S, Morino K, Hammond LE, Zhang D, Liu ZX, Romanelli AJ, Cline GW, Pongratz RL, Zhang XM, Choi CS, Coleman RA, Shulman GI: Prevention of hepatic steatosis and hepatic insulin resistance in mitochondrial acyl-CoA:glycerol-sn-3phosphate acyltransferase 1 knockout mice. Cell Metabolism 2005 , 2:55-65

58. Vergnes L, Beigneux AP, Davis R, Watkins SM, Young SG, Reue K: Agpat6 deficiency causes subdermal lipodystrophy and resistance to obesity. J Lipid Res 2006, 47:745-754

59. Michalek RD, Gerriets VA, Nichols AG, Inoue M, Kazmin D, Chang CY, Dwyer MA, Nelson ER, Pollizzi KN, Ilkayeva O, Giguere V, Zuercher WJ, Powell JD, Shinohara ML, McDonnell DP, Rathmell JC: Estrogen-related receptor-alpha is a metabolic regulator of effector T-cell activation and differentiation. Proc Natl Acad Sci U S A 2011, 108:18348-18353

60. Kim DK, Kim JR, Koh M, Kim YD, Lee JM, Chanda D, Park SB, Min JJ, Lee CH, Park TS, Choi HS: Estrogen-related receptor gamma (ERRgamma) is a novel transcriptional regulator of phosphatidic acid phosphatase, LIPIN1, and inhibits hepatic insulin signaling. J Biol Chem 2011, 286:38035-38042

61. Patch RJ, Searle LL, Kim AJ, De D, Zhu X, Askari HB, O'Neill JC, Abad MC, Rentzeperis D, Liu J, Kemmerer M, Lin L, Kasturi J, Geisler JG, Lenhard JM, Player MR, Gaul MD: Identification of diaryl ether-based ligands for estrogen-related receptor alpha as potential antidiabetic agents. J Med Chem 2011, 54:788-808 